\title{
Dependence of neutral winds on convection E-field, solar EUV, and auroral particle precipitation at high latitudes
}

\author{
Y. Deng ${ }^{1}$ and A. J. Ridley ${ }^{1}$ \\ Received 17 August 2005; revised 15 February 2006; accepted 24 February 2006; published 15 September 2006.
}

[1] We use the Global Ionosphere Thermosphere Model (GITM) to investigate the thermospheric neutral winds and their relationship to the high-latitude ionospheric convection, auroral precipitation, and solar activity. Each simulation is run for 24 hours, allowing an approximate steady state to be reached. Our results show that the duskside vortex and the antisunward polar cap neutral winds are prominent. The interplanetary magnetic field $(I M F)$ southward $B_{z}$ control of the polar cap winds is evident in both dusk cell and polar cap. When the IMF $B_{z}$ changes from -1 to $-10 \mathrm{nT}$, at the auroral region both the root of mean square $(R M S)$ of $V_{n}$ and $V_{i}$ increase more than $50 \%$ at $300 \mathrm{~km}$ altitude, the ratio of $R_{2}\left(R M S\left(V_{n} \cdot(E \times B)\right) / R M S(E \times B)^{2}\right)$ increases, while $R_{1}$ $\left(R M S\left(V_{n}\right) / R M S(E \times B)\right)$ changes little. In the polar cap region, since the ion flow is in the same direction as the neutral pressure gradient, above around $160 \mathrm{~km}$ altitude, $\left|V_{n}\right|$ is larger than $\left|V_{i}\right|$. When the $F_{10.7}$ increases from 70 to 250 , in the auroral region, the magnitude of $\left|V_{n}\right|$ increases close to $20 \%$ at $300 \mathrm{~km}$ altitude. At lower latitudes, where $\left|V_{n}\right|>\left|V_{i}\right|$ and the ions act as a load to the neutral winds, as a consequence of increases in $F_{10.7}$, the drag on the neutrals becomes greater and therefore slows the neutrals down. The altitude dependent change of $R_{2}$ is associated with the multiple effects of the $F_{10.7}$ to the neutral winds, including the increased day-to-night pressure gradient and ion drag. The impact of hemispheric power (HP) to the low thermosphere is pronounced. At $150 \mathrm{~km}$ altitude, the neutral winds increase $30 \%$ in magnitude at auroral latitudes. When HP is raised from 10 to $100 \mathrm{GW}$, a dawn cell forms, concurrent with an enhancement in the dusk cell. The dawn and dusk cells show an obvious asymmetry both in the average neutral winds and the sensitivity of neutral winds to the HP. It is shown that at $250 \mathrm{~km}$ altitude, the magnitude of the southward IMF $B_{z}$ has a positive correlation with the magnitude of the polar cap winds and the sensitivity increases with $F_{10.7}$. A negative correlation between the magnitude of $V_{n}$ and $F_{10.7}$ with small southward IMF $B_{z}$ becomes positive when the southward IMF $B_{z}$ increases. This change is presumably due to the momentum balance between ion drag and advection. The dawn (dusk) convection cell is enhanced when $B_{y}$ is negative (positive). In response to the effect of the Coriolis force, the $B_{y}$ negative winds are not exactly mirror reflections of the $B_{y}$ positive winds. For northward IMF Bz, the neutral winds flow sunward at the highest latitudes near noon. When the northward $B_{z}$ increases from $10 \mathrm{nT}$ to $20 \mathrm{nT}$, the distribution of the polar cap potential becomes more symmetric and the sunward neutral flow is enhanced and expanded.

Citation: Deng, Y., and A. J. Ridley (2006), Dependence of neutral winds on convection E-field, solar EUV, and auroral particle precipitation at high latitudes, J. Geophys. Res., 111, A09306, doi:10.1029/2005JA011368.

\section{Introduction}

[2] An understanding of both the thermosphere and ionosphere is important for a number of research and space weather applications, such as determining the influence of

\footnotetext{
${ }^{1}$ Center for Space Environment Modeling, University of Michigan, Ann Arbor, Michigan, USA.

Copyright 2006 by the American Geophysical Union. 0148-0227/06/2005JA011368
}

ionosphere on the magnetosphere, and examining satellite drag. The thermosphere and ionosphere are two overlapping regions of the atmosphere that are tightly coupled in many ways, including chemistry, momentum transference, and heating due to velocity differences. In this study, we examine the coupling due to the ions dragging the neutrals at high latitudes.

[3] Many studies have observationally investigated the neutral winds and how they are driven by the ionospheric convection [Aruliah et al., 1991; Brekke et al., 1974; Killeen 
et al., 1985; Kunitake and Schlegel, 1991; Lathuillère et al., 1997; McCormac et al., 1987, 1991; Meriwether, 1983; Meriwether and Shih, 1987; Mikkelsen et al., 1981; Niciejewski et al., 1992, 1994; Rees et al., 1986; Rothwell et al., 1974; Thayer et al., 1987; Zhang and Shepherd, 2000]. Measurements by ground-based Fabry-Perot interferometers (FPIs) and from the satellite instruments such as Dynamics Explorer 2 (DE2), Wind Imaging Interferometer (WINDII) have contributed much to our understanding of the thermospheric winds. Killeen et al. [1995] analyzed the upper thermospheric neutral winds and temperature measurements made by ground-based Fabry-Perot interferometers located at Thule, Greenland $\left(76.5^{\circ} \mathrm{N}, 69.0^{\circ} \mathrm{W}, \Lambda=86^{\circ}\right)$ and at Søndre Strømfjord, Greenland $\left(67.0^{\circ} \mathrm{N}, 50.9^{\circ} \mathrm{W}, \Lambda=74^{\circ}\right)$ from 1985 (near solar minimum) to 1991 (near solar maximum). The results show that the polar cap antisunward wind speed is a strong function of both solar and geomagnetic activity. The polar cap winds also show a pronounced dependence on the sign of the $B_{y}$ component of the interplanetary magnetic field (IMF). Thayer and Killeen [1991] used the neutral-wind measurements from the Dynamics Explorer-2 satellite to determine the divergence and vertical component of vorticity of the neutral winds in the upper thermosphere. They concluded that the mean neutral wind pattern is dominated by rotational flow rather than by divergent flow and the ratio of vorticity and divergence changes with geomagnetic conditions. Recently, Richmond et al. [2003] examined data from the WINDII instrument on the Upper Atmosphere Research Satellite (UARS). They conducted a study of the southern summer neutral wind patterns at a number of different altitudes and the influence of the IMF on these winds.

[4] One of the difficulties of data analysis studies is the lack of statistics to break the problem down into enough bins for a truly complete physical understanding of the system. For example, while the Richmond et al. [2003] study was extremely useful and showed very clear correlations, it was not able to separate out different seasons, different solar cycles, or even different auroral activity levels. In order to actually separate out these types of dependencies, one needs years and years of good data that cover a wide variety of conditions. One other way to examine these types of phenomena is the use of global models of the thermosphere and ionosphere.

[5] On the basis of wind data obtained from the AE-E and DE-2 satellites, the first edition of the horizontal wind model (HWM), an empirical model of the horizontal neutral wind in the upper thermosphere, was released in 1987 (HWM87) [Hedin et al., 1988] and intended for winds above $220 \mathrm{~km}$. Using the wind data from ground-based incoherent scatter radar and Fabry-Perot optical interferometers, HWM90 was extended down to $100 \mathrm{~km}$ [Hedin, 1992]. HWM93 [Hedin et al., 1996] was extended to the mesosphere and down to the ground with the inclusion of (medium-frequency) MF/meteor data. Seasonal/diurnal variations, solar activity variations, and magnetic activity variations have been included since HWM90. HWM93 describes the transition from predominately diurnal variations in the upper thermosphere to semidiurnal variations in the lower thermosphere and a transition from summer to winter flow above $140 \mathrm{~km}$ to winter to summer flow below. Comparison of the various data sets with the model shows remarkable agreement in general, particularly at middle and low latitudes [Hedin et al., 1996].

[6] Some studies [Rees et al., 1983; Roble et al., 1983, 1984] have shown that the winds calculated by the University of London Coupled Thermosphere Ionosphere Model (CTIM) and the National Center for Atmospheric Research (NCAR) Thermospheric General Circulation Model (TGCM) are consistent with measurements. At F region altitudes the neutral winds follow, but lag behind, the twocell ion convection. Killeen and Roble [1984] used a diagnostic package to calculate the magnitude and direction of the various terms in the hydrodynamic equation within the TGCM. The results show that at F region altitudes, the basic balance of forces is between ion drag and pressure, whereas at E region altitudes, Coriolis and advection forces also have significant contributions. On the basis of output from the NCAR-TGCM, a model of the global, timedependent, thermospheric horizontal vector neutral winds and neutral temperature fields was constructed [Killeen et al., 1987]. The wind field is presented by a vector spherical harmonic (VSH) expansion. The results from the VSH model show a good agreement with global-scale wind measurements from the Dynamics Explorer (DE-2) satellite.

[7] We use the Global Ionosphere Thermosphere Model (GITM) to investigate the thermospheric neutral winds and their relationship to the high-latitude ionospheric convection, auroral precipitation and $F_{10.7}$. Various factors make our work of particular value for the study of ionosphere and thermosphere coupling: (1) We totally separate the dependences of solar cycle, cross polar cap potential, and auroral precipitation, which has not yet been done by others. (2) By modeling a large number of theoretical time periods using idealized input conditions, we gain very comprehensively quantitative results of how the ion drag driven neutral winds vary with altitude, solar cycle, cross polar cap potential, and auroral precipitation. (3) We not only examine the dawndusk asymmetry but also investigate the difference between auroral region and polar cap. (4) GITM is a new model, so this study serves as a statistical validation of the neutral winds within the model.

\section{Methodology}

\subsection{Model Description}

[8] GITM is a three-dimensional spherical code that models the Earth's thermosphere and ionosphere system using a stretched grid in latitude and altitude [Ridley et al., 2006]. One major difference between GITM and other thermosphere codes is that GITM uses an altitude grid and does not have the hydrostatic assumption. The simulation can be initiated using MSIS and IRI neutral and ion densities for the given date and time. It can also be restarted from a previous state. The code can use a dipole magnetic field, a tilted dipole or the IGRF magnetic field with the APEX coordinate system [Richmond, 1995].

[9] GITM can be run using results from the assimilative mapping of ionospheric electrodynamics (AMIE) technique [Richmond and Kamide, 1988; Richmond, 1992] as highlatitude drivers in realistic, highly dynamic time periods. It can also use the Weimer [1996] or Ridley et al. [2000] electrodynamic potential patterns and the Fuller-Rowell and Evans [1987] particle precipitation patterns for more ideal- 

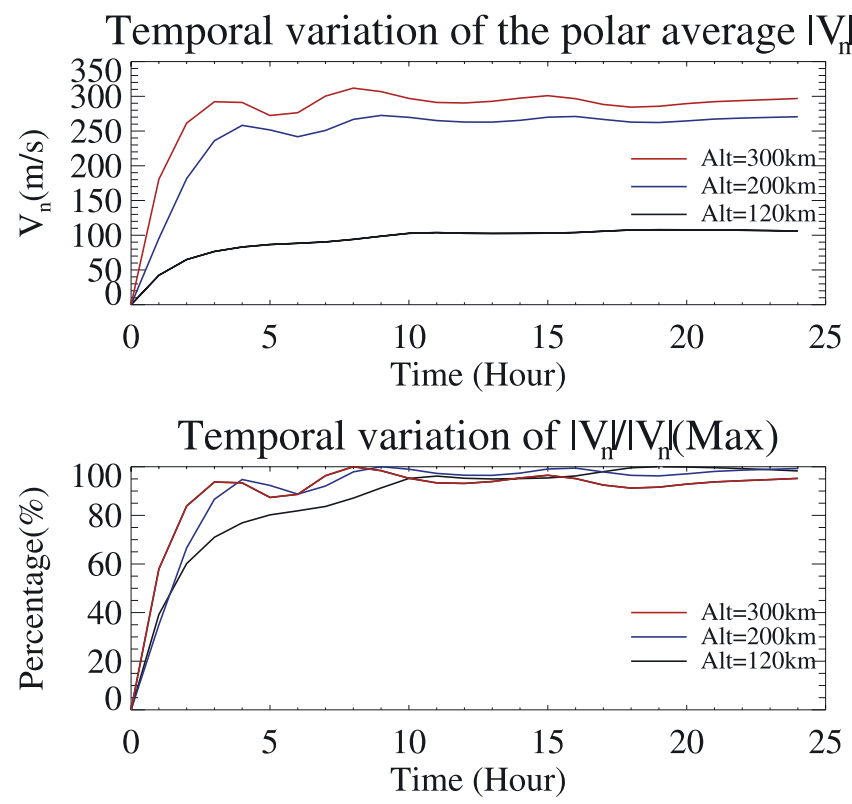

Figure 1. (top) Temporal variation of the polar average neutral wind magnitudes at 120, 200, and $300 \mathrm{~km}$. (bottom) Temporal variation of the normalized neutral wind speeds $\left(\left|V_{n}\right| /\left|V_{n}(\operatorname{Max})\right|\right)$, where $\left|V_{n}(\operatorname{Max})\right|$ is the maximum speed in the 24 hours at every altitude.

ized conditions. The model is also coupled to the University of Michigan's global magnetohydrodynamic (MHD) model of the magnetosphere [Gombosi et al., 2004]. This allows investigation of the coupling between the thermosphereionosphere and magnetosphere systems. Model equations are described in Appendix A.

[10] There are some limitations to the GITM code. For example, we have not yet included any low-latitude electrodynamics, and the self-consistent low-latitude electrodynamics is what differentiates the TIGCM from the TIEGCM. While this is very important for studies focusing on the equatorial or low-latitude region, we are concentrating on the high-latitude region for this study. For more details of GITM, please refer to Ridley et al. [2006].

\subsection{Simulation Conditions and Analysis Procedure}

[11] The simulations described in this study are all started using MSIS and IRI, with a simple dipole field model and static neutrals. We run 24 hours to allow the neutral winds to reach a quasi-steady state. To determine whether the simulations have run to a steady state or not, line plots of average wind speeds at different altitudes are examined, as shown in Figure 1. From the time plots we determine the neutral winds' ramp-up time. At $300 \mathrm{~km}$ altitude, neutral winds get ramped up in 3 hours, which is faster than that at $200 \mathrm{~km}$ (4 hours) and $120 \mathrm{~km}$ (10 hours). Figure 2 shows that the ramp-up time is decreasing with altitude, and above $120 \mathrm{~km}$ after 12 hours the neutral winds reach steady state. It is interesting that there are some oscillations of neutral winds speed at 200 and $300 \mathrm{~km}$ altitudes, as shown in Figure 1. This could be associated with the ring effect, caused by the traveling atmospheric disturbances (TADs) and represented as waves meridionally transferred around the Earth, when we change the IMF $B_{z}$ suddenly at the starting point. In this paper, we restrict our study to the equinox cases. The analysis of the seasonal variation is one of our future plans. The resolution is $2.5^{\circ}$ latitude by $5^{\circ}$ longitude by 0.25 scale height.

[12] The primary drivers of the thermosphere and ionosphere are solar EUV and geomagnetic activity (convection electric field and auroral particle precipitation). In this study, we use the Weimer [1996] electrodynamic potential patterns, prescribed by the IMF and solar wind velocity, and the Fuller-Rowell and Evans [1987] particle precipitation patterns, specified by the HP, as the high-latitudes drivers. Therefore the IMF only affects the convection patterns and IMF changes are equivalent to the high-latitude convection E-field variations in our simulations. This is different from the statistical results [Akasofu, 1976; Hardy et al., 1985], which also show a strong correlation between IMF and auroral particle precipitation.

[13] When the IMF $B_{z}$ turns negative, the increased dayside magnetic reconnection rate increases the magnetospheric convection [Axford and Hines, 1961] and also enhances the energy input from the solar wind into the magnetosphere, which is partly dissipated in the ionosphere through the auroral particle precipitation [Akasofu, 1964]. Both the convection and particle precipitation strongly affect the geomagnetic activity, which is denoted by $K_{p}$ index. Statistical results show a strong correlation between IMF (or convection E-field) and auroral particle precipitation [Hardy et al., 1985]. Nevertheless, in a physical sense,

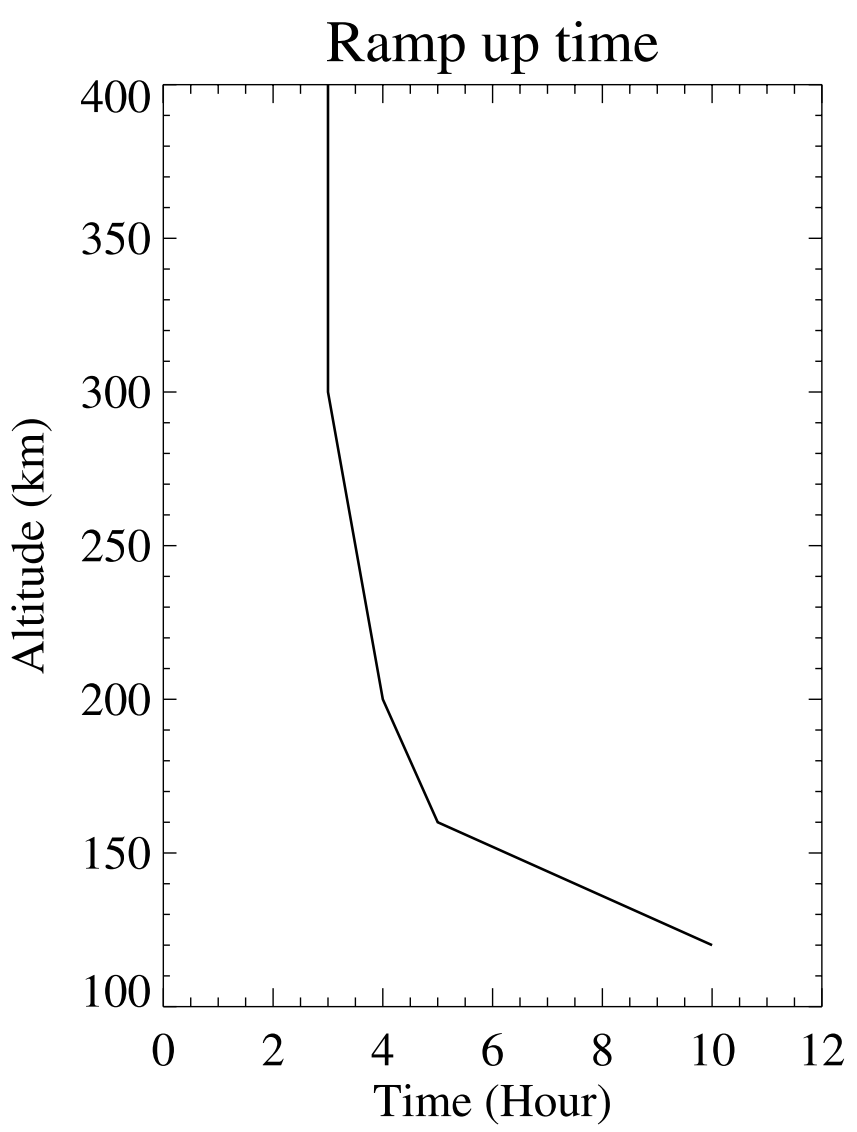

Figure 2. The neutral winds ramp-up time variation with the altitude. 

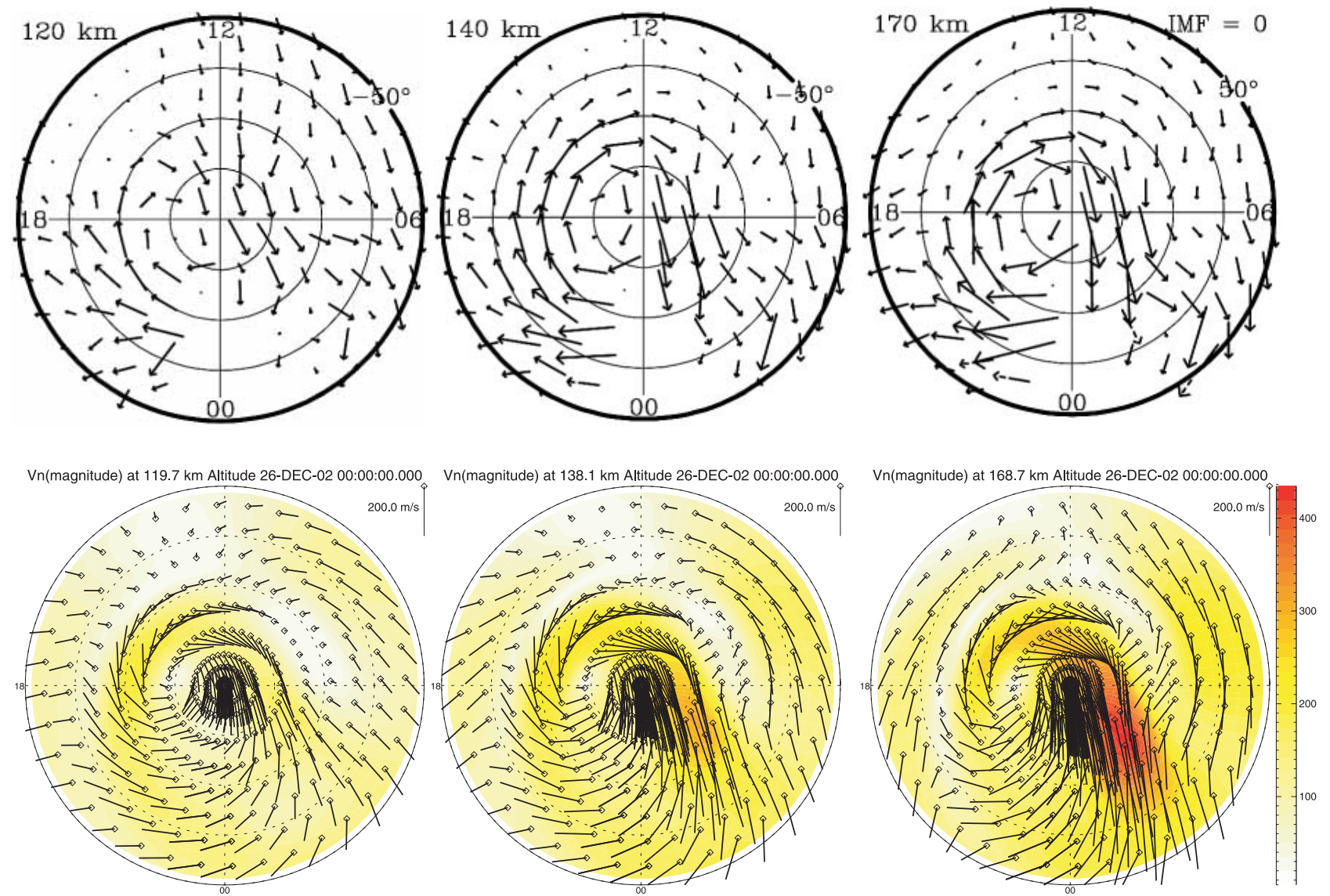

Figure 3. Compare the neutral wind simulation results of GITM (bottom) with the observations from WINDII (top) [Richmond et al., 2003] at three different altitudes: $120 \mathrm{~km}, 140 \mathrm{~km}$, and $170 \mathrm{~km}$. Both of them are in the southern polar region and southern summer time for quiet conditions (IMF $=0$ ). In both cases the outside rings are $50^{\circ}$. The vectors show the horizontal neutral winds on the scale indicated on the plots. The small squares are the start points of the vectors. The color contours show the magnitude of the horizontal neutral winds with the same legend.

they have no direct connection. For example, in steady magnetospheric convection (SMC) events, the auroral particle precipitation changes little, while IMF $B_{z}$ is strongly southward and the cross-polar cap potential is elevated [Sergeev et al., 1996]. In our simulations, we study some idealized cases, treating convection E-field and auroral particle precipitation as two independent inputs. This is because we want to separate the effect of increased convection E-field from that of auroral particle precipitation variation. It is hard to separate them in data analysis since the two are statistically linked, but relatively easy using a theoretical model, which helps us to extract a physical understanding of the problem.

[14] In order to systematically determine how the different levels of constant ion forcing alter the thermospheric neutral winds and thermospheric state, we run a large number of periods using constant forcing terms. From run to run, we vary the strength of the forcing to determine the effect of this forcing on the global system. For example, we hold the $F_{10.7}$ and auroral inputs constant and increase the cross polar cap potential from small values up to large values, as shown in Figure 4, where the cross polar cap changes from $40 \mathrm{kV}$ to $120 \mathrm{kV}$. In order to simplify, we set IMF $B_{y}=0$ for all the cases in sections $3.2-3.5$ and discuss a little the effect of $B_{y}$ in section 3.6. We then hold the electric potential and auroral inputs constant and alter the $F_{10.7}$ to determine the effect of the solar activity on the coupled system. We repeat the experiment by altering the auroral inputs, once again using the coupling to other models to allow easy access to different particle precipitation models. Once we have done these three series of runs, we start filling in the cross terms which allow us to fully quantify the effects of these different forcing terms on the thermosphere-ionosphere system. This provides a more theoretical extension to the observational (and theoretical) work that other researchers have done regarding the dependence of the neutral winds on the IMF [e.g., Richmond et al., 2003, and references within].

[15] We calculate the root of mean square (RMS) of neutral wind, ion convection, and $\mathbf{E} \times \mathbf{B}$ drift to show the average characteristics of neutral winds. As shown in Figure 5, we also compute ratios:

$$
R_{1}=\frac{R M S\left(V_{n}\right)}{R M S(E \times B)}
$$


(A)Polar Cap Potential $\left(\mathrm{B}_{\mathrm{z}}=-1 \mathrm{nT}\right)$

Potential(V) at $298.6 \mathrm{~km}$ Altitude 19-MAR-02 00:00:00.000

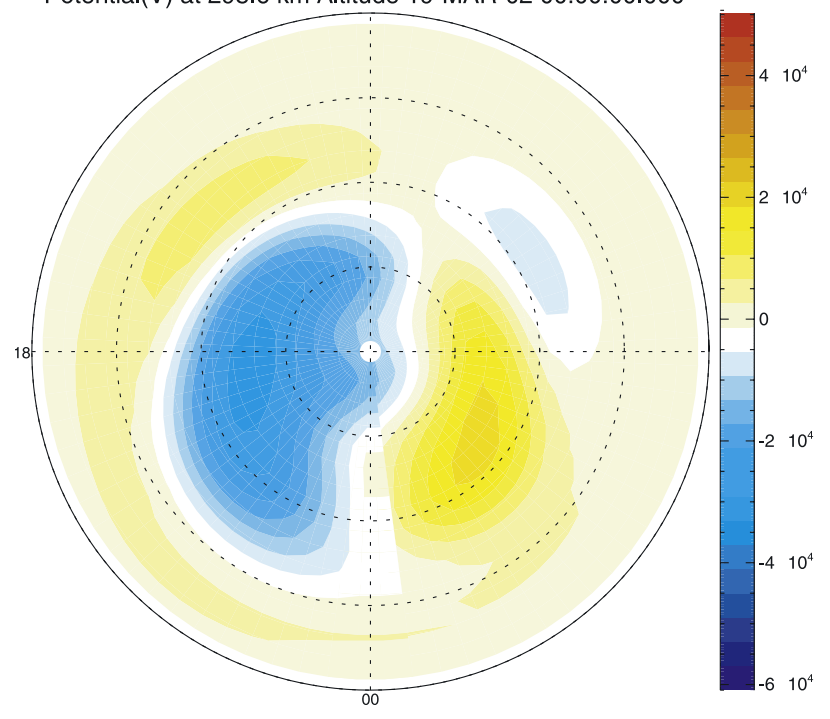

(C)Polar Cap Potential $\left(\mathrm{B}_{\mathrm{Z}}=-10 \mathrm{nT}\right)$

Potential(V) at 298.6 km Altitude 19-MAR-02 00:00:00.000

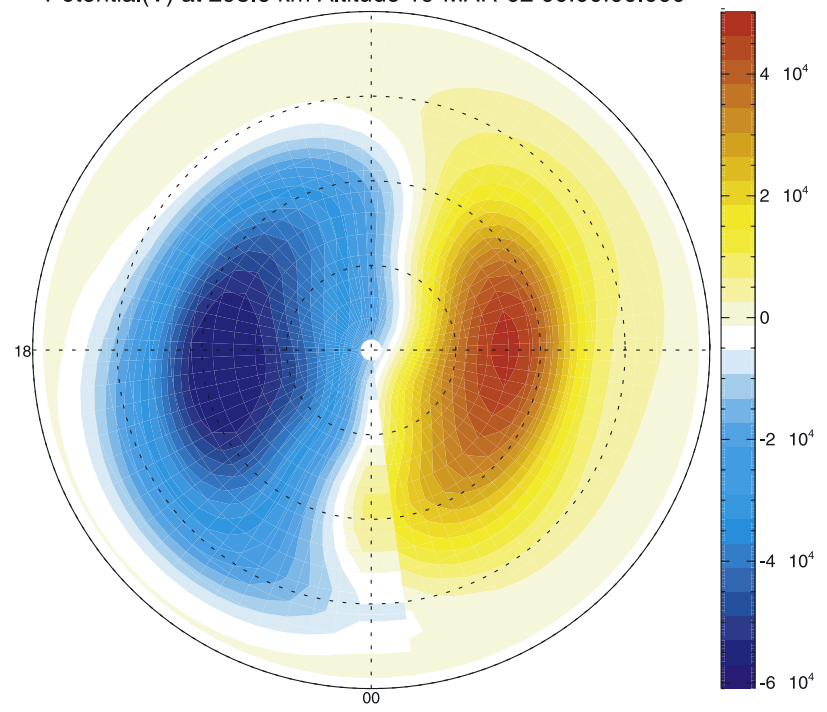

(B) $\mathrm{V}_{\mathrm{n}}\left(\mathrm{B}_{\mathrm{z}}=-1 \mathrm{nT}\right)$

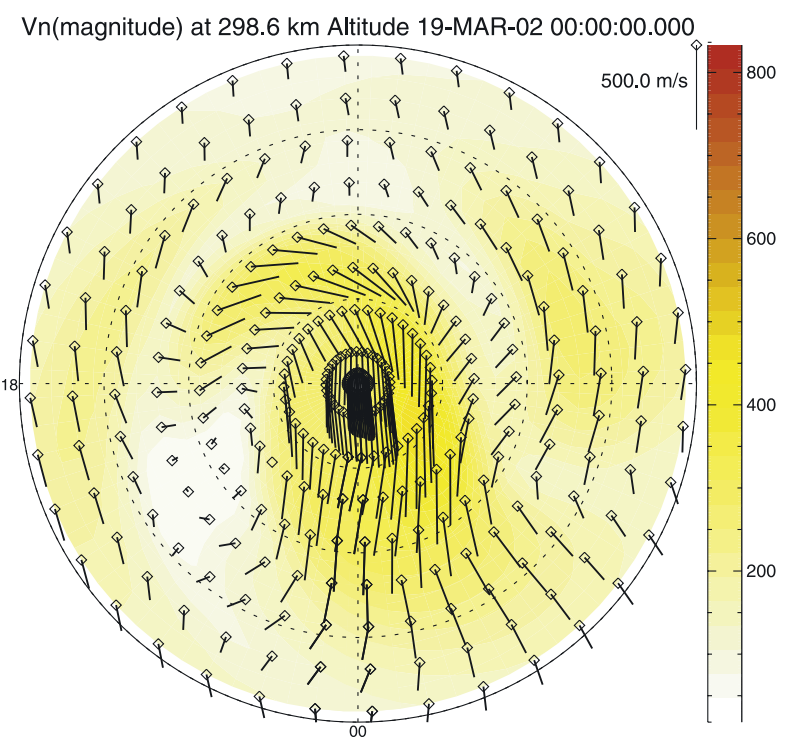

(D) $\mathrm{V}_{\mathrm{n}}\left(\mathrm{B}_{\mathrm{Z}}=-10 \mathrm{nT}\right)$

$\mathrm{Vn}$ (magnitude) at 298.6 km Altitude 19-MAR-02 00:00:00.000

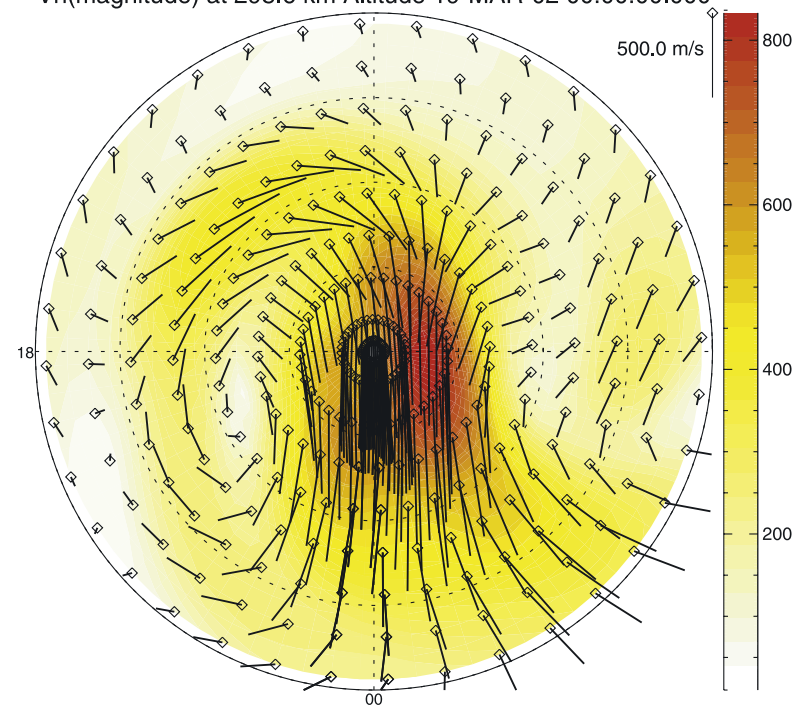

Figure 4. The effect of IMF $B_{z}$ to the polar region neutral winds when IMF $B_{z}$ changes from $-1 \mathrm{nT}$ (top) to $-10 \mathrm{nT}$ (bottom) and holding $F_{10.7}=150, \mathrm{HP}=10 \mathrm{GW}$. (left) The distribution of polar cap potential poleward of $50^{\circ} \mathrm{N}$ in the spring time. (right) The vectors show the horizontal neutral winds and the small squares are the start points of the vectors. The color contours show the magnitude of the horizontal neutral winds $V_{n}$.

and

$$
R_{2}=\frac{R M S\left(V_{n} \cdot(E \times B)\right)}{R M S(E \times B)^{2}}
$$

to see how well the neutral winds and ion convection velocities are coupled. $R_{1}$ is the ratio of the mean wind speed to the mean ionospheric convection speed, which other studies calculated when they analyzed observational data. It is an easy way to show the correlation but only takes into account the effect of magnitudes. $R_{2}$ shows the correlation between the neutral and ionospheric convection velocities, accounting for the difference of directions as well as magnitude differences. $R_{2}$ may be a better way to describe the correlation because it includes both the effects of magnitude and direction differences between neutral and ion velocities. Richmond et al. [2003] suggested the use of $R_{2} / R_{1}$ as correlation coefficient, which is related to the relative angle between neutral and ion velocities. It is specifically valuable to describe the correlation in the sunward ion convection region where the ion-drag force of neutral atmosphere is opposite to the 
thermal pressure gradient. Therefore in this study, we analyze both $R_{1}$ and $R_{2}$.

\section{Results}

\subsection{Comparing Simulation Results With Observation Data}

[16] In order to show that our model results match the observations, we compare them with Richmond et al. [2003], which shows the analyzed results from the WINDII instrument. Figure 3 shows the wind patterns in the summer southern polar region at three different altitudes: $120 \mathrm{~km}$, $140 \mathrm{~km}$, and $170 \mathrm{~km}$. The top panel is WINDII data with zero IMF, while the bottom panel is the simulation results with IMF $B_{y}=0 \mathrm{nT}$ and $B_{z}=-0.1 \mathrm{nT}$ (IMF $=0$ is not a valid input for the Weimer [1996] model).

[17] As shown in Figure 3, both the WINDII data and the simulation results change significantly with altitude. At $120 \mathrm{~km}$ altitude, the comparison shows that the observation and simulation are similar in the following aspects: (1) In the polar cap and early morning sectors, both have strong antisunward winds; (2) In the 1800-0000 LT sector, both show apparent sunward flow; (3) In the dawn sector, the antisunward winds are dominant in both; and (4) The reversals between sunward and antisunward flow at dusk occur at the same latitude. The differences are as follows: (1) At midnight, in GITM simulation results, there are westward winds which do not appear in the WINDII measurement; and (2) In the afternoon sector, the sunward winds are larger in the GITM than in the WINDII measurements. At 140 and $170 \mathrm{~km}$ altitude, the dusk cell of clockwise winds becomes stronger with increasing altitude and there is a strong equatorward flow in the early morning region. The maximum neutral wind is larger in GITM than in WINDII. Richmond et al. [2003] mentioned that in the DE-2 observations shown by Killeen et al. [1995], the early morning antisunward winds are also stronger than the results in the work of Richmond et al. [2003]. This quantitative difference could be due to some slight difference of the conditions. In general, GITM is very consistent with the observations.

\subsection{Convection E-Field Dependence}

[18] Since the change of IMF is equivalent to the convection E-field variation in our simulation, as mentioned in section 2.2, we specify the convection E-field by IMF. For simplification, in this subsection, we only investigate the southward IMF $B_{z}$ situations, when plasma convection at high latitudes exhibits a 2-cell pattern with antisunward flow over the polar cap and return flow in the lower latitudes [Schunk and Nagy, 2000]. Through ion-neutral collisions, the ion convection strongly influences the thermospheric neutral winds and the ion drag force efficiently makes the neutral winds follow the ion convection pattern at high altitudes. Figure 4 shows the neutral wind patterns for two levels of southward $B_{z}$ and $B_{y}=0$ in geomagnetic polar coordinates at $300 \mathrm{~km}$ altitude. The $B_{z}$ control of the neutral winds is very evident, specifically in the dusk and polar cap regions. When the $B_{z}$ changes from $-1 \mathrm{nT}$ to $-10 \mathrm{nT}$, the cross polar cap potential increases from $40 \mathrm{kV}$ to $120 \mathrm{kV}$. In the dusk cell, not only does the magnitude of the neutral winds increase greatly, but the range of the dusk cell expands equatorward also. In the polar cap region, the maximum speed increases from $460 \mathrm{~km} / \mathrm{s}$ to $830 \mathrm{~km} / \mathrm{s}$. On the dawnside, while there is no closed cell, the antisunward flow has turned to being almost poleward.

[19] In our analysis we differentiate between the auroral zone and the polar cap and analyze each separately. This is for two reasons: (1) in the polar cap, the ion flow is in the same direction as the neutral pressure gradient, while in the auroral zone and at slightly lower latitudes, the ion flow can be antiparallel to the neutral pressure gradient; and (2) there is little precipitation in the polar cap, while there are differing levels of precipitation in the auroral zone. One would therefore expect that the neutral winds would have differing sensitivities in these two regions. To show this sensitivity, we calculate the zonal average (root of the mean square) of neutral wind, ion convection, and $\mathbf{E} \times \mathbf{B}$ drift in the auroral region, where the ion drift is sunward. We loosely define the auroral zone as being $65^{\circ}-70^{\circ}$ latitude. As shown in Figure $5 \mathrm{a}, \mathbf{E} \times \mathbf{B}$ drift describes the ion convection pretty well above $150 \mathrm{~km}$ altitude, even though there is an obvious difference between ion convection and $\mathbf{E} \times \mathbf{B}$ drift at low altitude, associated with the contribution of other forces to the ion velocity. When we compare the $B_{z}=$ $-1 \mathrm{nT}$ run (blue lines) with the $B_{z}=-10 \mathrm{nT}$ run (red lines) in Figure $5 \mathrm{a}$, both the neutral winds and ion drifts increase more than $50 \%$ at the altitude of $300 \mathrm{~km}$. In order to show the coupling between neutral winds and ion drifts, we calculate the ratios of $R_{1}$ (equation (1))and $R_{2}$ (equation (2)). In the auroral region (Figure $5 \mathrm{~b}$ ) the ratio of the neutral wind and $\mathbf{E} \times \mathbf{B}$ magnitudes (i.e., $R_{1}$ ) shows little dependence on $B_{z}$, while $R_{2}$, taking into account the contribution of the angle between them, shows a much stronger dependence. Increasing $R_{2}$ with constant $R_{1}$ indicates the direction of neutral wind has been rotated closer to the direction of ion convection, especially between $150 \mathrm{~km}$ and $200 \mathrm{~km}$ altitude: when $B_{z}=$ $-1 \mathrm{nT}, R_{2}<0$, implying that on average, the angle between the neutral and ion velocities is larger than $90^{\circ}$. However, when $B_{z}=-10 \mathrm{nT}$, the importance of ion-drag force increases, making $R_{2}>0$ at all altitudes.

[20] In the polar cap, the neutral winds are always maximized and play an important role in the magnetosphere-ionosphere coupling. Therefore we calculate the RMS and ratios in the polar cap region (defined as poleward of $80^{\circ}$ ). It is noteworthy that $\left|V_{n}\right|>\left|V_{i}\right|$ at high altitudes in Figure 5c. The turning point from $\left|V_{n}\right|<\left|V_{i}\right|$ to $\left|V_{n}\right|>\left|V_{i}\right|$ is around $160 \mathrm{~km}$. Below this point the ion-drag is a positive force to neutral winds, but above it, the ion-drag is a negative force. These results are consistent with Killeen and Roble [1984], who also showed that in the polar cap the ion drag force is antiparallel to the neutral winds at $300 \mathrm{~km}$. $\left|V_{n}\right|>\left|V_{i}\right|$ has also been observed in satellite data [Deng et al., 1993; Gary et al., 1994] and explained as the fly-wheel effect when the convection E-field is suddenly weakened. However, our results show that when the altitude is high enough, $\left|V_{n}\right|>\left|V_{i}\right|$ is no longer a temporary phenomena, it may happen as a steady state condition.

[21] A possible interpretation is that in the polar cap, the ion flow is in the same direction as the neutral pressure gradient. At E-region altitudes, although both ion drag and pressure gradient force accelerate the neutral wind, they must be in balance with other relevant forces, like Coriolis and advection. Therefore it is difficult for the neutral wind 
(A) Root Mean Square (Auroral Region)

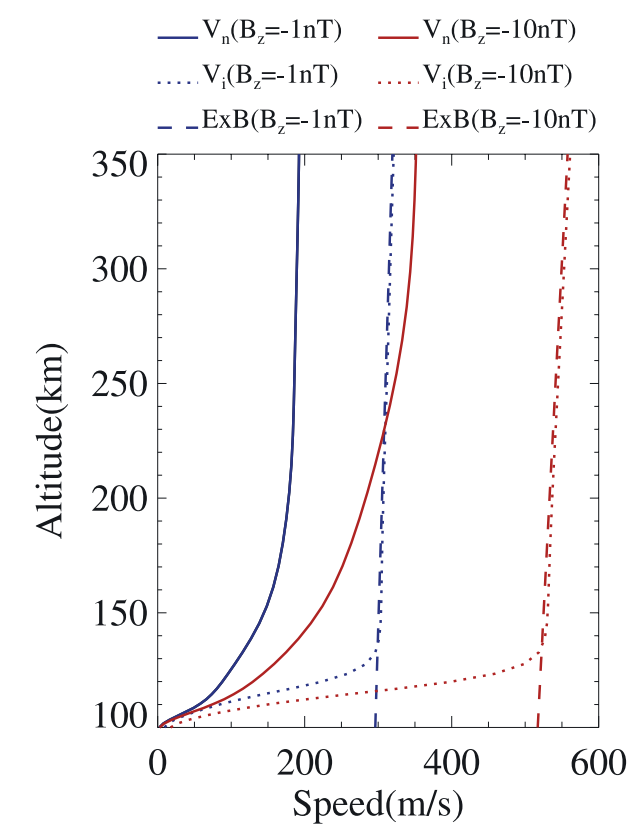

(C) Root Mean Square (Polar Cap Region)

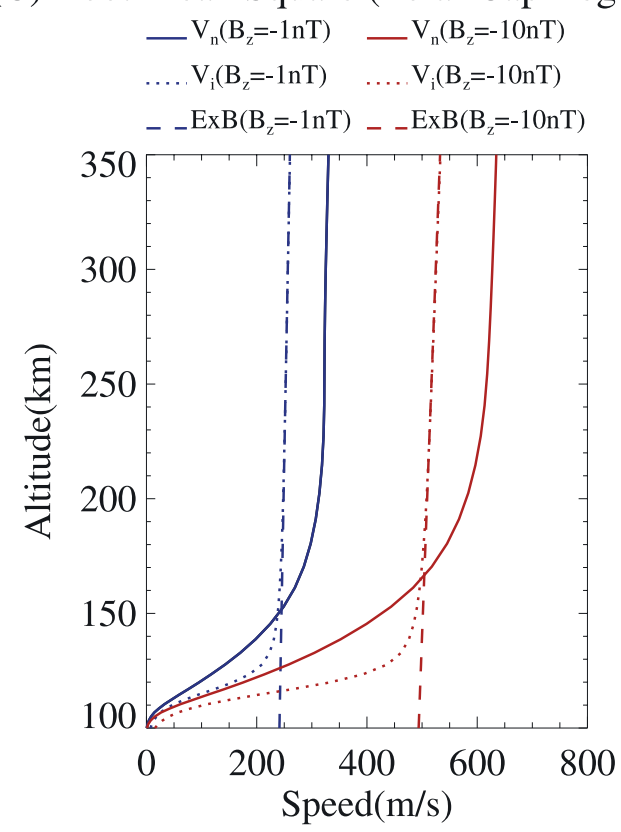

\section{(B) Ratio (Auroral Region)}

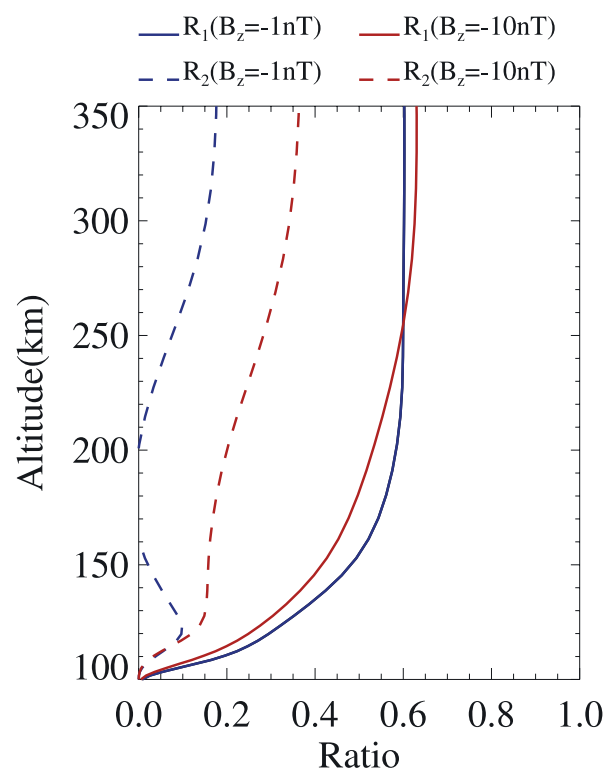

(D) Ratio (Polar Cap Region)

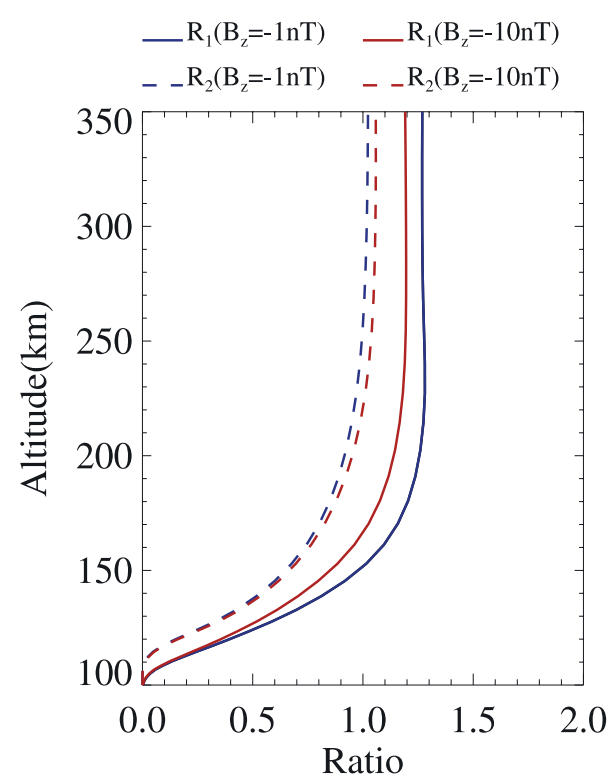

Figure 5. (a) Root of mean square (RMS) of neutral winds (solid), ion convection (dot) and $\mathbf{E} \times \mathbf{B}$ drift (dash) in the auroral region (lat $\left[65^{\circ}, 70^{\circ}\right]$ ) when $\operatorname{IMF}\left(B_{z}\right)=-1 \mathrm{nT}, F_{10.7}=70, \mathrm{HP}=10 \mathrm{GW}$ (blue); and $\operatorname{IMF}\left(B_{z}\right)=-10 \mathrm{nT}, F_{10.7}=70, \mathrm{HP}=10 \mathrm{GW}$ (red). (b) The ratio of $R_{1}=\frac{R M S\left(V_{n}\right)}{R M S(E \times B)}$ (solid) and $R_{2}=\frac{R M S\left(V_{n} \cdot(E \times B)\right)}{R M S(E \times B)^{2}}$ (dash). (c) the same as Figure 5a except in the polar cap region (poleward of $80^{\circ}$ ).

(d) The same as Figure $5 \mathrm{~b}$ except in the polar cap region (poleward of $80^{\circ}$ ).

velocity to exceed the ion convection velocity in the Eregion. At F-region altitudes, however, the basic balance of forces is between ion drag and pressure gradient. The neutral wind velocity is accelerated to be larger than $V_{i}$, and the consequent ion drag force on the neutral is in the opposite direction to the pressure gradient and large enough to balance it.

\subsection{Solar EUV Dependence}

[22] Variations of the solar EUV activity directly affect the ion density distributions. The neutral wind is affected as a consequence of the variation of ion-neutral collision frequency. Figure 6 shows the neutral wind profiles for two levels of $F_{10.7}$ at $300 \mathrm{~km}$ altitude. When the $F_{10.7}$ increases from 70 to 250 , the total ion density in the dayside 


$$
\text { (A) }[\mathrm{e}]\left(\mathrm{F}_{10.7}=70\right)
$$

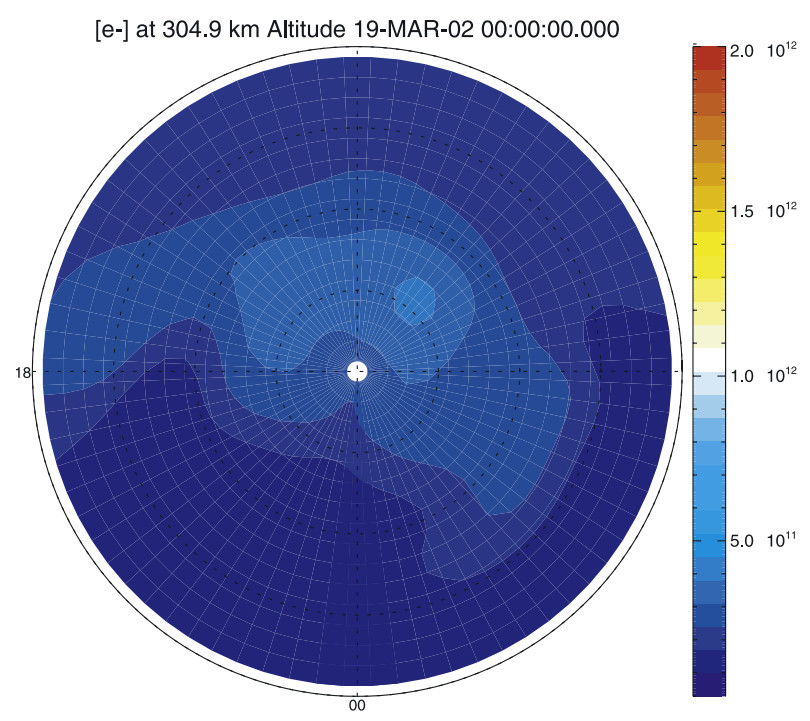

(C) $[\mathrm{e}]\left(\mathrm{F}_{10.7}=250\right)$

[e-] at $299.5 \mathrm{~km}$ Altitude 19-MAR-02 00:00:00.000

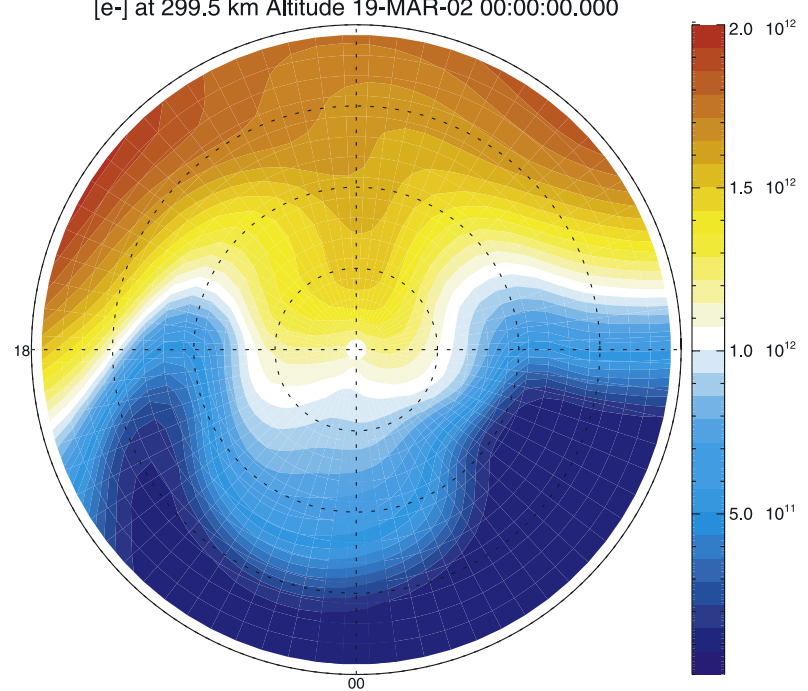

(B) $\mathrm{V}_{\mathrm{n}}\left(\mathrm{F}_{10.7}=70\right)$

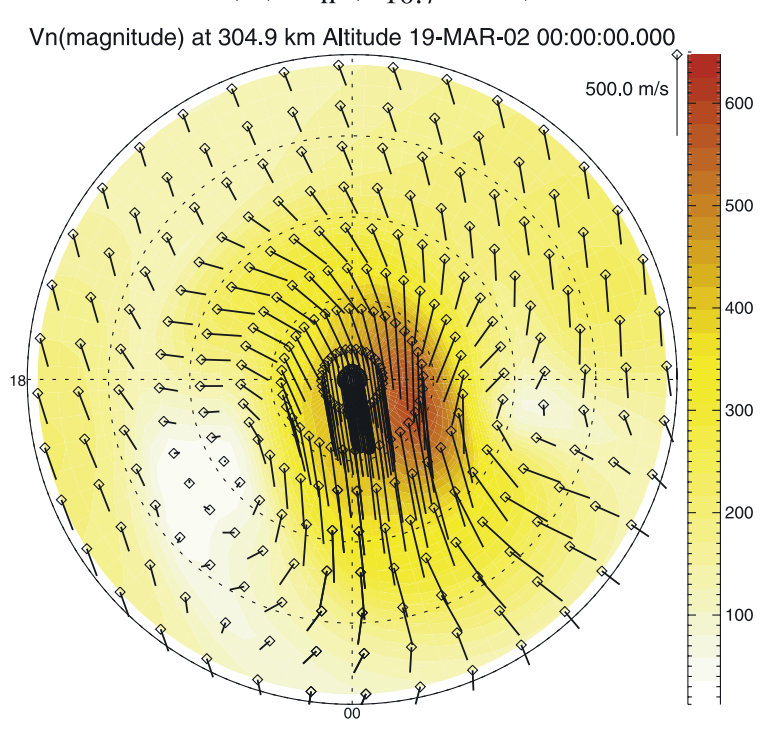

(D) $\mathrm{V}_{\mathrm{n}}\left(\mathrm{F}_{10.7}=250\right)$

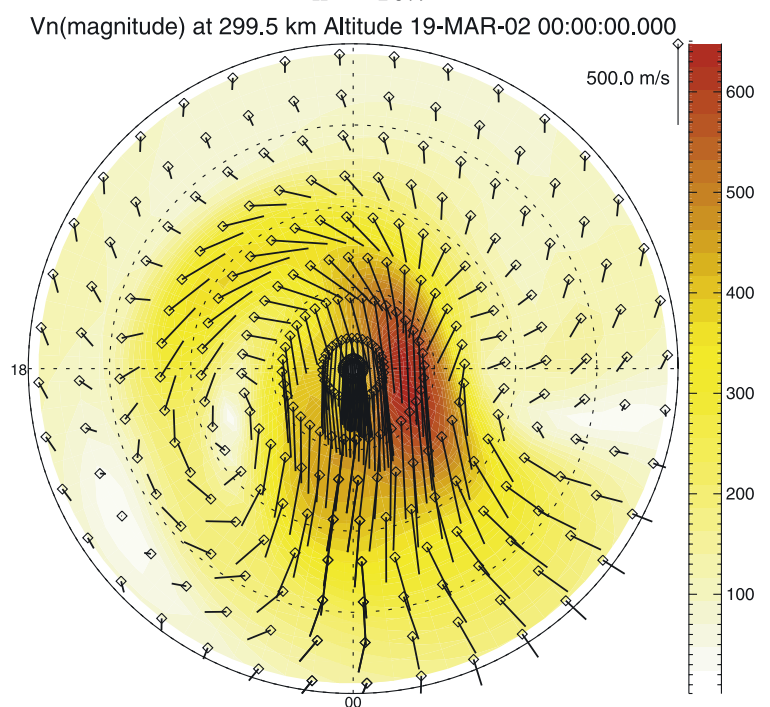

Figure 6. The effect of $F_{10.7}$ to the polar region neutral winds when $F_{10.7}$ changes from 70 (top) to 250 (bottom) holding IMF $B_{z}=-05 \mathrm{nT}, \mathrm{HP}=10 \mathrm{GW}$. (left) Distribution of electron density poleward of $50^{\circ} \mathrm{N}$ in the spring time. (right) The vectors show the horizontal neutral winds and the small squares are the start points of the vectors. The color contours show the magnitude of the horizontal neutral winds.

increases greatly: for example, at noon and $50^{\circ}$ latitude it changes from $2.1 \times 10^{11} \mathrm{~m}^{-3}$ to $1.7 \times 10^{12} \mathrm{~m}^{-3}$. Owing to the strong antisunward ion convection, a tongue of ion density appears in the polar cap in Figure 6c. This indicates the importance of advection term in the continuity equation. The comparison between Figure $6 \mathrm{~b}$ and Figure $6 \mathrm{~d}$ shows that in response to the increased coupling, the dusk cell neutral winds increase when the $F_{10.7}$ increases. However, on the dayside at latitudes below $65^{\circ}$, the neutral wind speed actually decreases when the $F_{10.7}$ rises. This anticorrelation has also been observed by Millstone Hill's Fabry-Perot Interferometer [Emmert et al., 2003]. The possible reason is that in this region the $E \times B$ ion drift is essentially zero, therefore $\left|V_{i}\right|<\left|V_{n}\right|$, and the ions act as a load to the neutral winds. As the $F_{10.7}$ increases, the dayside electron density increases, hence the drag on the neutrals becomes greater and slows the neutrals down. In the postmidnight sector at lower latitudes, since the electron density changes little, there is little change in the neutral winds.

[23] This is also true at latitudes below the auroral zone. The neutrals are driven primarily by the balance of the gradient in pressure force and the drag by the (almost) stationary ions. Other forces, such as the Coriolis force, 


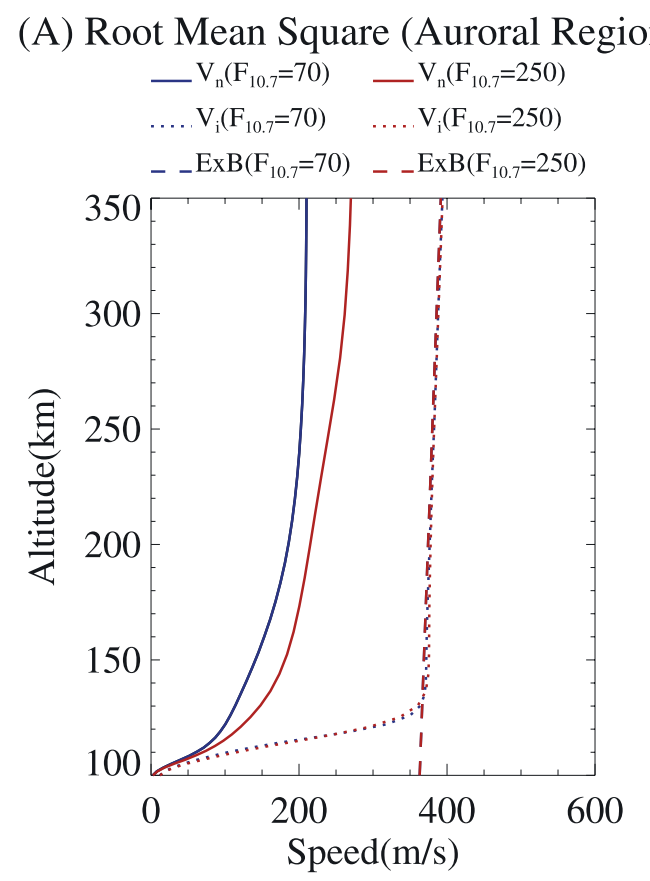

(C) Root Mean Square (Polar Cap Region)

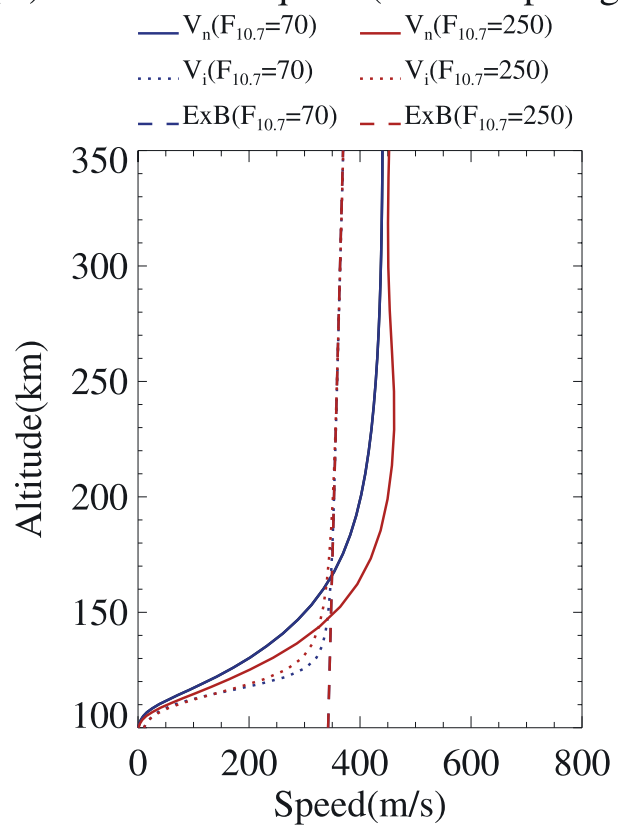

(B) Ratio (Auroral Region)

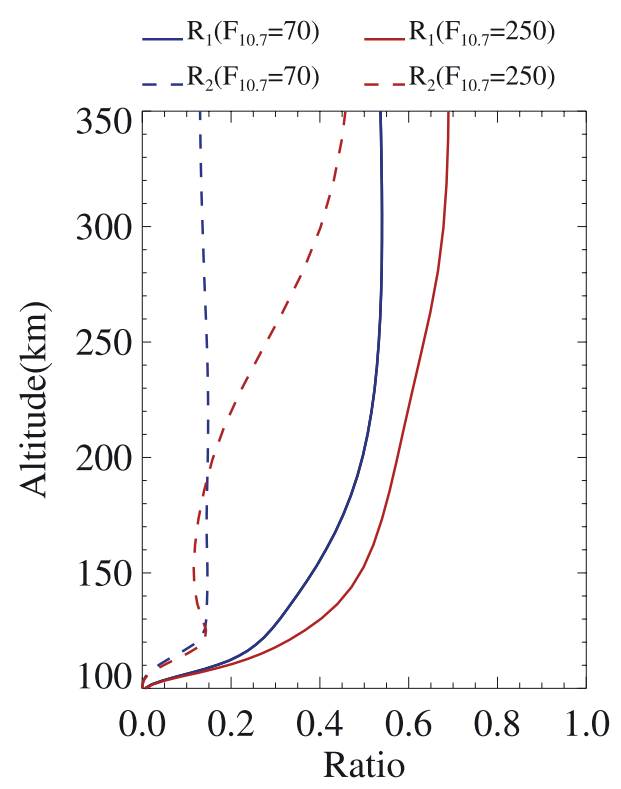

(D) Ratio (Polar Cap Region)

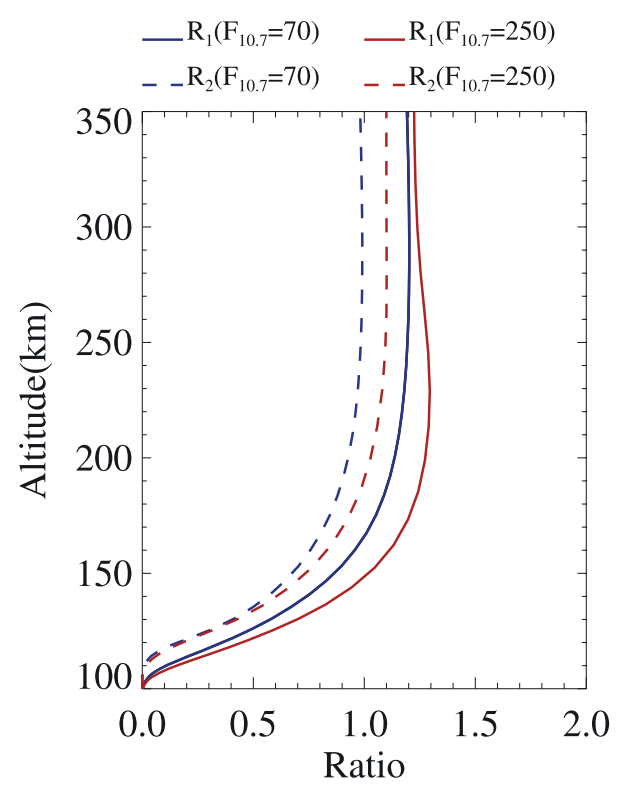

Figure 7. (a) Root of mean square $(R M S)$ of neutral winds (solid), ion convection (dot), and $\mathbf{E} \times \mathbf{B}$ drift (dash) in the auroral region (lat $\left[65^{\circ}, 70^{\circ}\right]$ ) when $\operatorname{IMF}\left(B_{z}\right)=-5 \mathrm{nT}, F_{10.7}=70, \mathrm{HP}=10 \mathrm{GW}$ (blue); and $\operatorname{IMF}\left(B_{z}\right)=-5 \mathrm{nT}, F_{10.7}=250, \mathrm{HP}=10 \mathrm{GW}$ (red). (b) The ratio of $R_{1}=\frac{R M S\left(V_{n}\right)}{R M S(E \times B)}$ (solid) and $R_{2}=\frac{R M S\left(V_{n} \cdot(E \times B)\right)}{R M S(E \times B)^{2}}$ (dash). (c) the same as Figure 7a except in the polar cap region (poleward of $80^{\circ}$ ). (d) the same as Figure $7 \mathrm{~b}$ except in the polar cap region (poleward of $80^{\circ}$ ).

influence the direction of the neutral flow, but the magnitude of the flow is primarily determined by the gradient in pressure and the ion drag: thus the neutral wind is typically stronger than the ion flow at lower latitudes.

[24] Owing to the increased coupling between ions and neutrals, the $R M S$ of neutral winds in the auroral region increases almost $20 \%$ at $300 \mathrm{~km}$ altitude, while the $R M S$ of the ion drift does not change a great deal, as shown in Figure 7a. It is noted that $\mathbf{E} \times \mathbf{B}$ drifts are identical in the two cases. However, Peymirat et al. [2002] and Ridley et al. [2003] show that the neutral winds can induce 6-10\% difference of the polar cap potential through changing the coupling between the ionosphere and magnetosphere and hence changes the $\mathbf{E} \times \mathbf{B}$ drift. This discrepancy is 
(A) $[\mathrm{e}](\mathrm{HPI}=10 \mathrm{GW})$

[e-] at 152.9 km Altitude 19-MAR-02 00:00:00.000

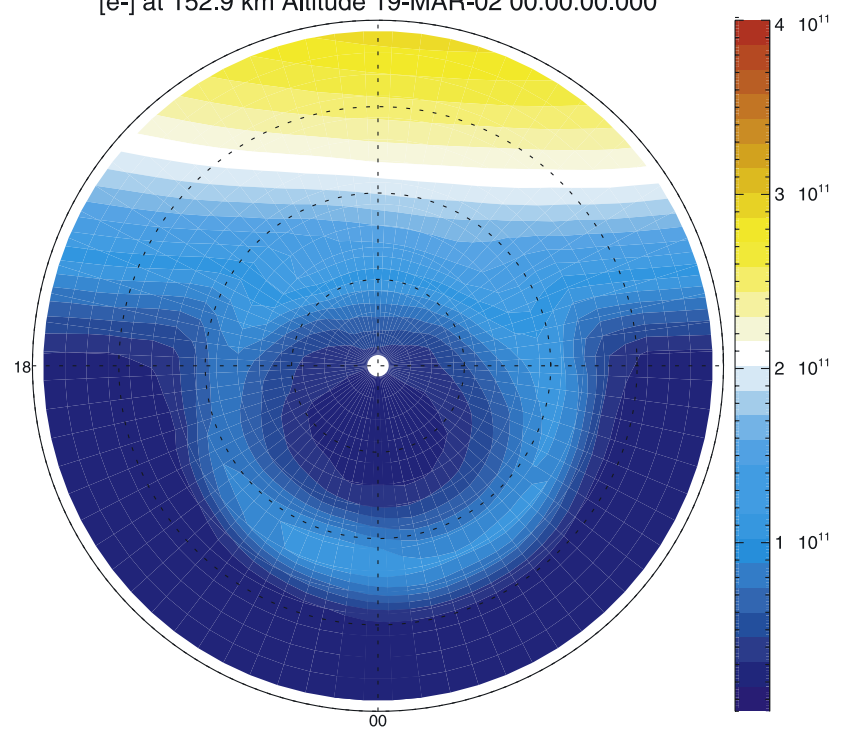

(C) $[\mathrm{e}](\mathrm{HPI}=100 \mathrm{GW})$

[e-] at 152.9 km Altitude 19-MAR-02 00:00:00.000

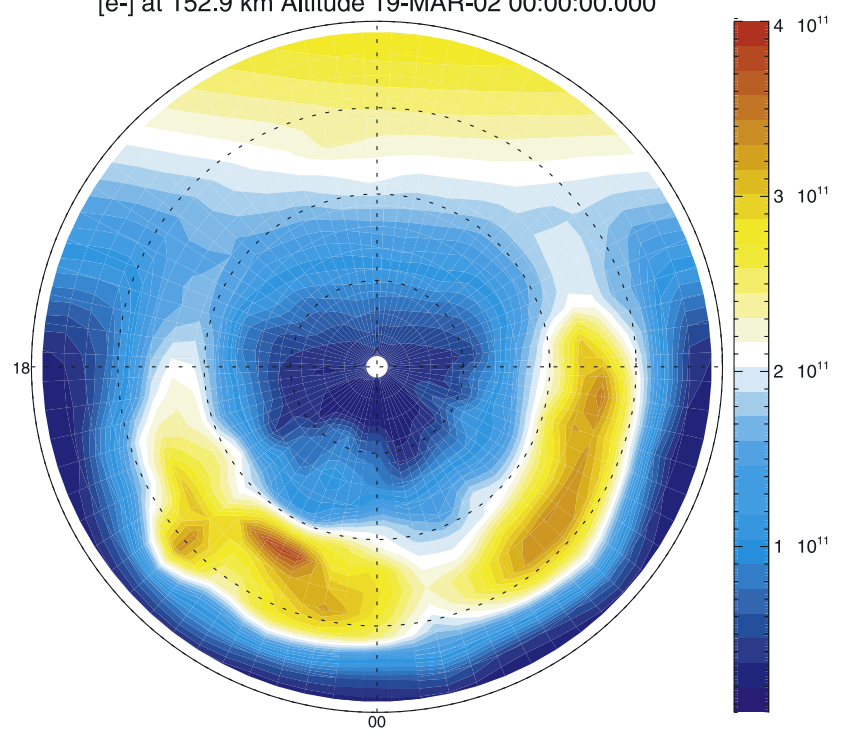

(B) $\mathrm{V}_{\mathrm{n}}(\mathrm{HPI}=10 \mathrm{GW})$

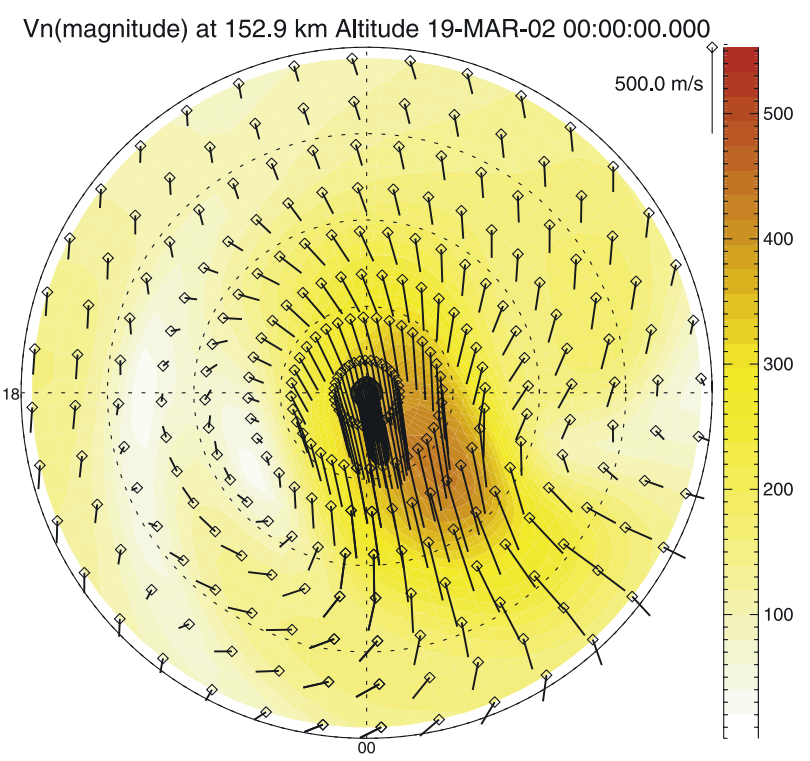

(D) $\mathrm{V}_{\mathrm{n}}(\mathrm{HPI}=100 \mathrm{GW})$

$\mathrm{Vn}$ (magnitude) at 152.9 km Altitude 19-MAR-02 00:00:00.000

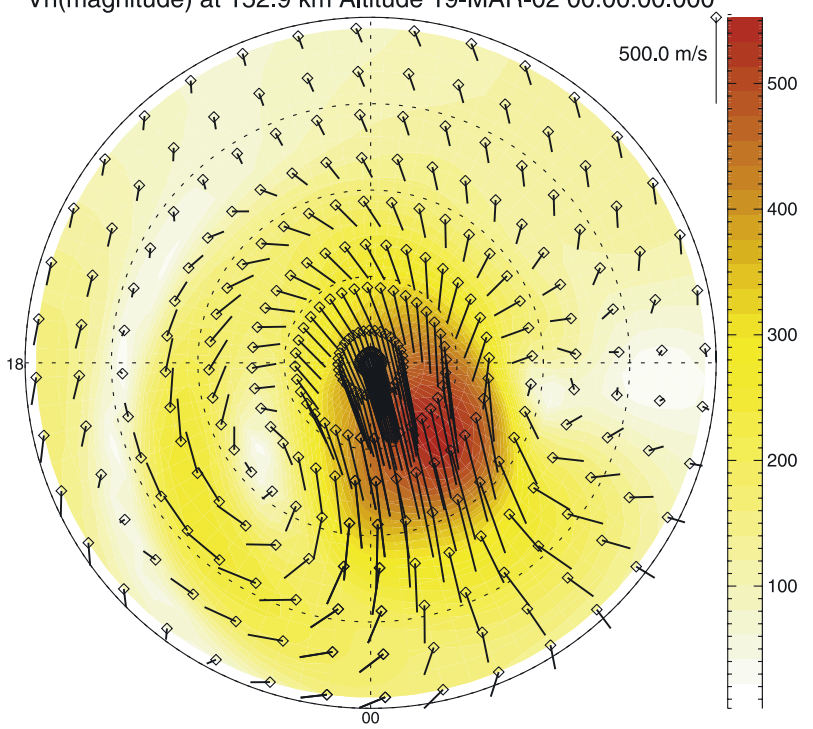

Figure 8. The effect of HP to the polar region neutral winds when the HP changes from 10 (top) to $100 \mathrm{GW}$ (bottom) holding $F_{10.7}=150$, IMF $B_{z}=-5 \mathrm{nT}$. (left) Distribution of electron density poleward of $50^{\circ} \mathrm{N}$ in the spring time. (right) The vectors show the horizontal neutral winds and the small squares are the start points of the vectors. The color contours show the magnitude of the horizontal neutral winds.

attributed to the simplification we used in this study. To obtain the polar cap potential, we use the Weimer [1996] model, which does not include the dynamo effect of the neutral winds on the polar cap potential. The effect of $F_{10.7}$ to the neutral winds is complex. When $F_{10.7}$ increases, the EUV heating and neutral temperature in the dayside increase, and hence the pressure gradient force increases. Meanwhile, $F_{10.7}$ also increases the ion-drag force through the increasing ion density. In the auroral region, these two forces are in the opposite directions. The net effect of $F_{10.7}$ is due to the sum of these two forces. In order to examine the relative importance of these two forces, the altitude profile of the neutral-ion correlation coefficient, $R_{2}$, is shown in Figure $7 \mathrm{~b}$. When the $F_{10.7}$ ascends from 70 to $250, R_{2}$ increases significantly above $200 \mathrm{~km}$, which indicates the change of the ion-drag force is dominant. How- 


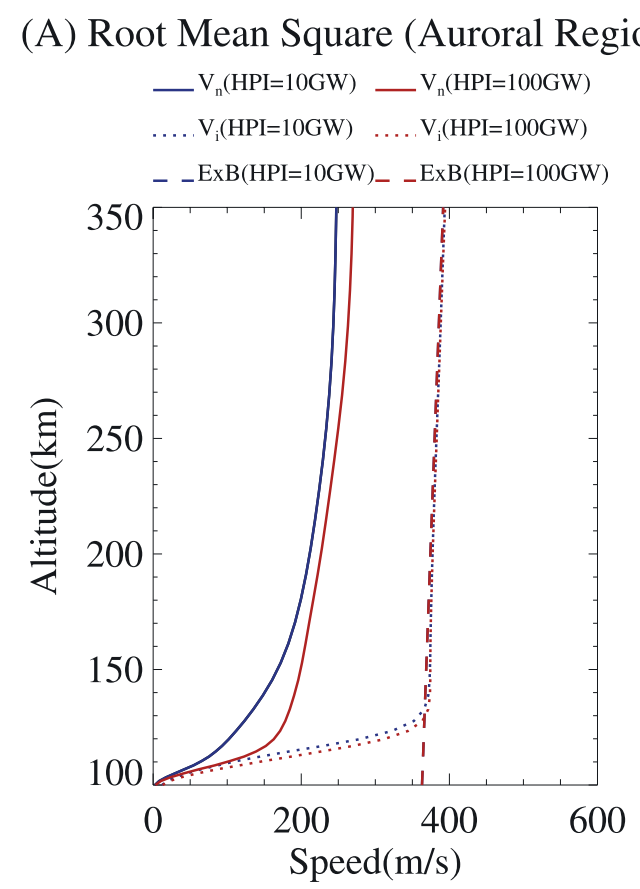

\section{(B) Ratio (Auroral Region)}

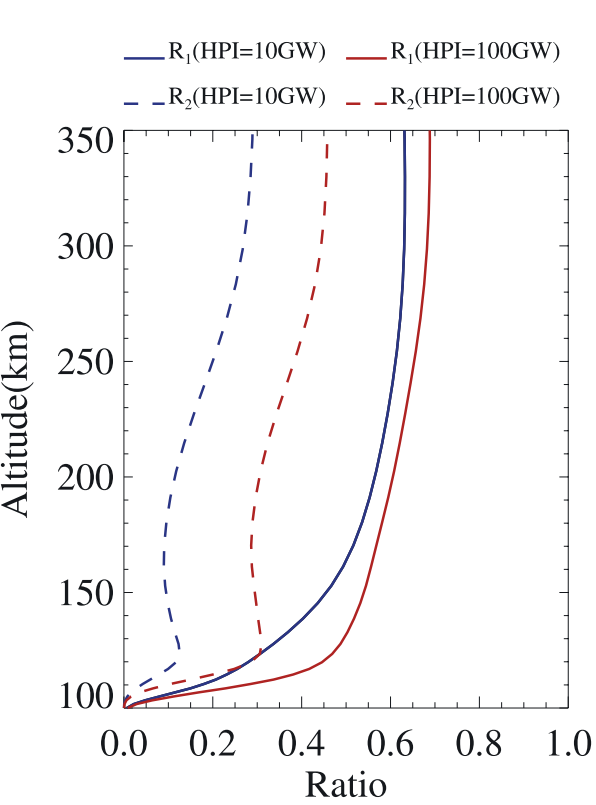

(C) Root Mean Square (Polar Cap Region)

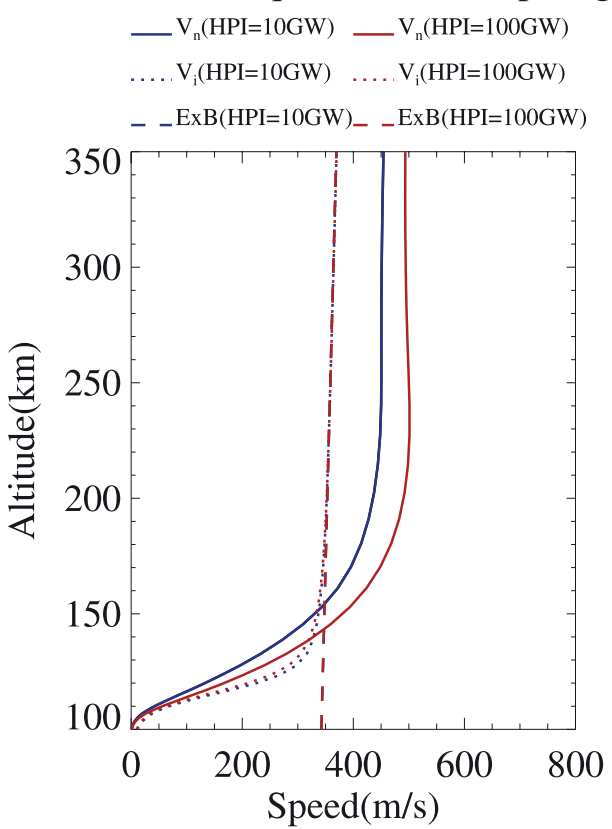

\section{(D) Ratio (Polar Cap Region)}

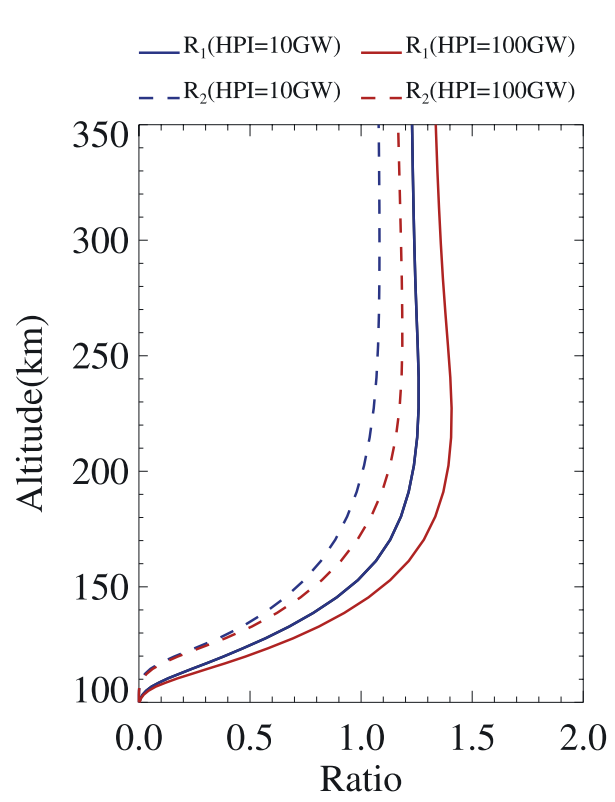

Figure 9. (a) Root of mean square (RMS) of neutral winds (solid), ion convection (dot) and $\mathbf{E} \times \mathbf{B}$ drift (dash) in the auroral region (lat $\left[65^{\circ}, 70^{\circ}\right]$ ) when $\operatorname{IMF}\left(B_{z}\right)=-5 \mathrm{nT}, F_{10.7}=150$, HP $=10 \mathrm{GW}$ (Blue); and $\operatorname{IMF}\left(B_{z}\right)=-5 \mathrm{nT}, F_{10.7}=150, \mathrm{HP}=100 \mathrm{GW}$ (Red). (b) The ratio of $R_{1}=\frac{R M S\left(V_{n}\right)}{R M S(E \times B)}$ (solid) and $R_{2}=\frac{R M S\left(V_{n} \cdot(E \times B)\right)}{R M S(E \times B)^{2}}$ (dash). (c) the same as Figure 9a except in the polar cap region (poleward of $80^{\circ}$ ). (d) the same as Figure $9 \mathrm{~b}$ except in the polar cap region (poleward of $80^{\circ}$ ).

ever, $R_{2}$ decreases between $120 \mathrm{~km}$ and $200 \mathrm{~km}$, the altitudes between the E- and F-region, where the ion drag may be minimized and the pressure gradient force increases more. In the polar cap, as shown in Figure $7 \mathrm{c}$, the ion velocity is lower during higher $F_{10.7}$ at low altitudes. This is due to the increased drag on the ions at low altitudes. Under the conditions that $\rho_{i} \nu_{i n} \gg e N_{e} B$ and $e N_{e} \mathbf{E}$ is the dominant force, we simplify the expression for the ion velocity from the equation (A4) in Appendix A as $V_{i}=\frac{e \mathbf{E}}{M_{i} v_{i n}}$. When $\nu_{i n}$ gets larger, as it does for larger $F_{10.7}, V_{i}$ decreases. However, this is not true for HP runs in the auroral zone, as shown in Figure 9a. The $V_{i}$ increases when the HP increases at low 

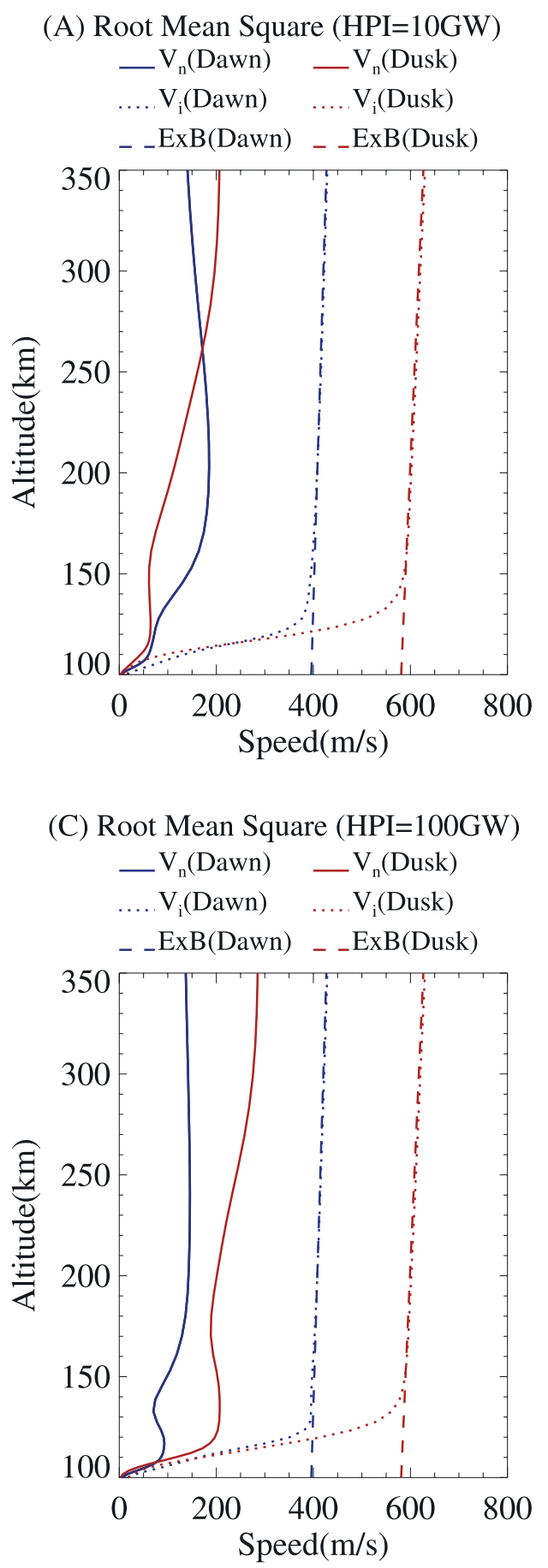

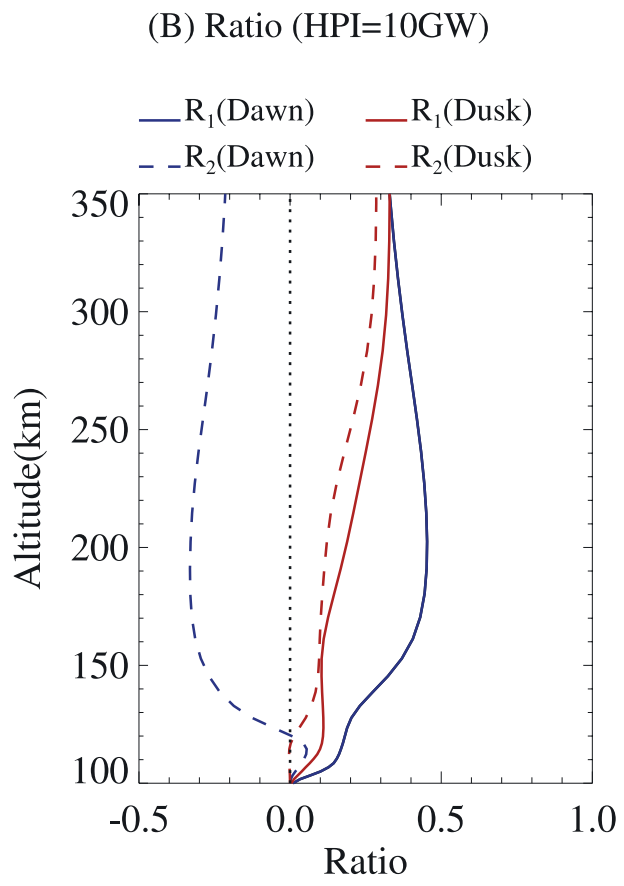

(D) Ratio (HPI=100GW)

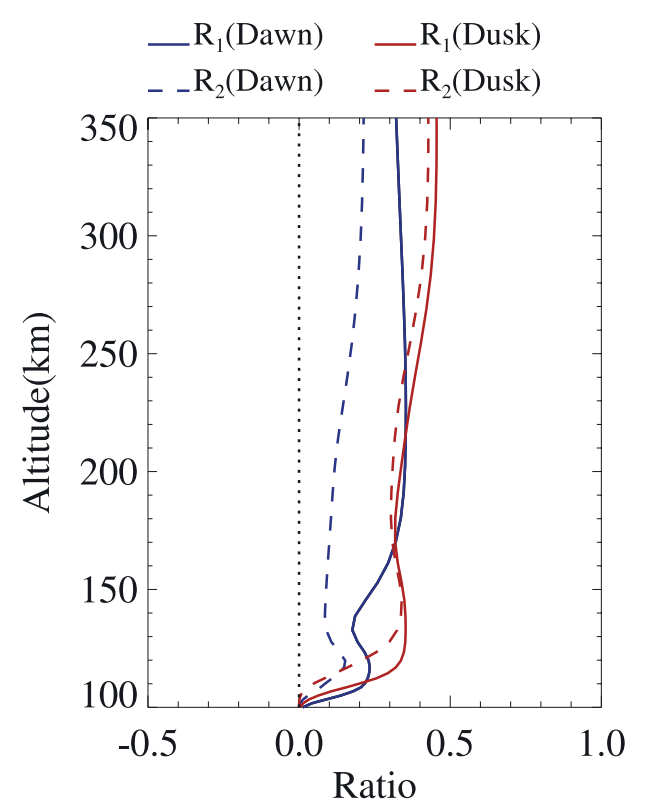

Figure 10. (a) Root of mean square $(R M S)$ of neutral winds (solid), ion convection (dot) and $\mathbf{E} \times \mathbf{B}$ drift (dash) in the dawnside (Lat $\left[65^{\circ}, 70^{\circ}\right], \operatorname{LT}[4,8]$ ) (blue) and duskside (Lat $\left[65^{\circ}, 70^{\circ}\right], \mathrm{LT}[16,20]$ ) (red) when $\operatorname{IMF}\left(B_{z}\right)=-5 \mathrm{nT}, F_{10.7}=150, \mathrm{HP}=10 \mathrm{GW}$. (b) The ratio of $R_{1}=\frac{R M S\left(V_{n}\right)}{R M S(E \times B)}$ (solid), $R_{2}=\frac{R M S\left(V_{n} \cdot(E \times B)\right)}{R M S(E \times B)^{2}}$ (dash) in the dawnside (blue) and duskside (red). The dot black line shows the position of ratio $=0$. (c) the same as Figure 10a except $\mathrm{HP}=100 \mathrm{GW}$. (d) the same as Figure 10b except $\mathrm{HP}=100 \mathrm{GW}$.

altitude. This could be related to the role that $V_{n}$ plays. When the neutral wind effect can not be ignored, the ion velocity, $V_{i}=\frac{e \mathbf{E}}{M_{i} v_{i n}}+V_{n}$, has a positive relationship with the neutral wind.

\subsection{Auroral Particle Precipitation Dependence}

[25] The total hemispheric power (HP) is computed from satellite measurements of high latitude (above about $45^{\circ}$ of magnetic latitudes) precipitating energy flux carried by ions and electrons. It strongly affects the ion densities in 
$\mathrm{F}_{10.7}=70$

$\mathrm{V}_{\mathrm{n}}=302.5+26.75 \mathrm{~B}_{\mathrm{z}}$

$(\mathrm{R}=0.999)$

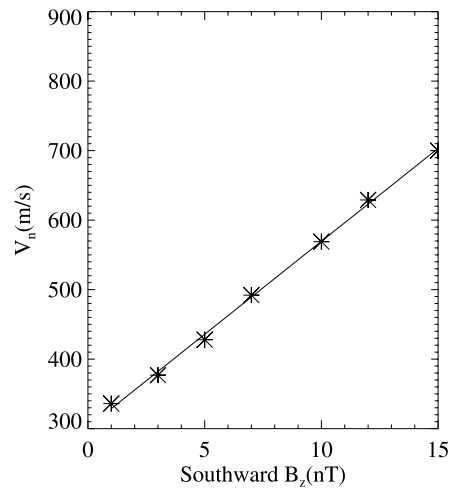

$\mathrm{B}_{\mathrm{Z}}=-1 \mathrm{nT}$

$\mathrm{V}_{\mathrm{n}}=342.65-0.105 \mathrm{~F}_{10.7}$

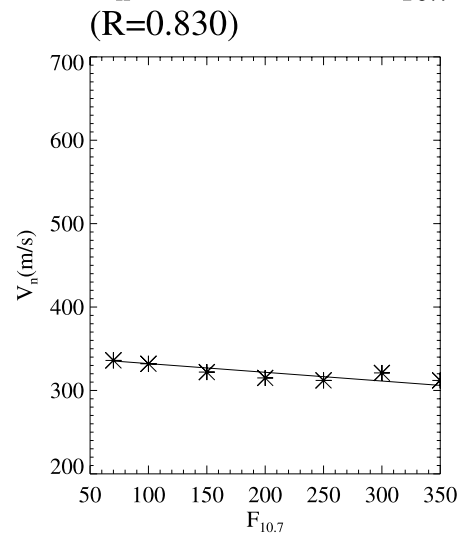

$\mathrm{F}_{10.7}=150$

$\mathrm{V}_{\mathrm{n}}=282.5+33.75 \mathrm{~B}_{\mathrm{z}}$

$(\mathrm{R}=0.999)$

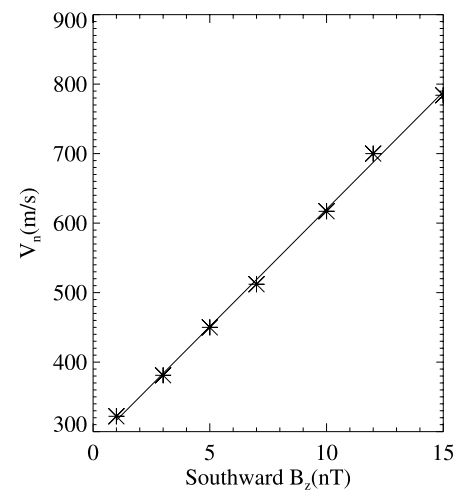

$\mathrm{B}_{\mathrm{Z}}=-5 \mathrm{nT}$

$\mathrm{V}_{\mathrm{n}}=424.93+0.139 \mathrm{~F}_{10.7}$

$(\mathrm{R}=0.916)$

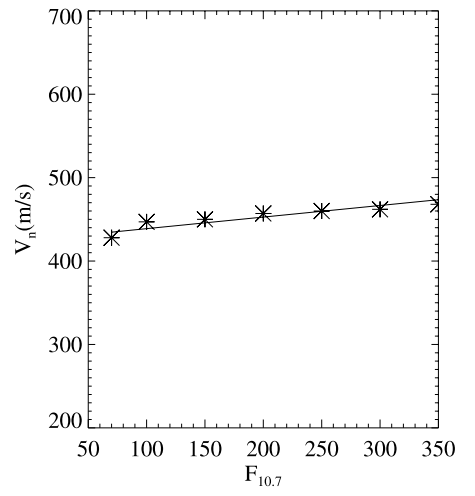

$\mathrm{F}_{10.7}=250$

$\mathrm{V}_{\mathrm{n}}=277.5+36.75 \mathrm{~B}_{\mathrm{Z}}$

$(\mathrm{R}=0.999)$

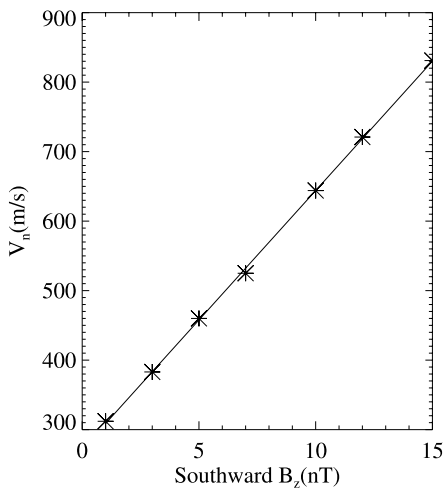

$$
\begin{aligned}
& \mathrm{B}_{\mathrm{z}}=-10 \mathrm{nT} \\
& \mathrm{V}_{\mathrm{n}}=563.38+0.313 \mathrm{~F}_{10.7} \\
& (\mathrm{R}=0.966)
\end{aligned}
$$

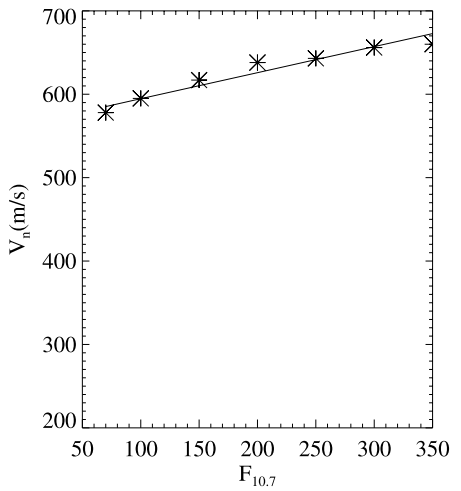

Figure 11. Linear fits to the magnitude of the average antisunward polar cap winds (poleward $80^{\circ}$ ) at $250 \mathrm{~km}$ altitude when $F_{10.7}$ and the magnitude of the southward IMF $B_{z}$ change. The corresponding equations with linear correlation coefficients are at the top of the figures.

the auroral region and hence affects the neutral winds through changing the ion-neutral collision frequency. Figure 8 shows that in response to this change in HP, the dusk cell increases in size and wind velocities, and a significant dawn cell circulation is established (contrasting with the lack of such a feature in Figure 4 and Figure 6). This indicates that around equinox, the magnitude of HP has a particularly pronounced effect on the dawn-cell circulation.

[26] Since the precipitating particles primarily change the ion densities in the low thermosphere region, the effect of HP on the neutral wind is apparent below $170 \mathrm{~km}$, as shown in Figure 9a. For example, at $150 \mathrm{~km}$ the neutral winds increase approximately $30 \%$. However, above $200 \mathrm{~km}$ altitude, the effect is modest. $R_{1}$ in Figure $9 \mathrm{~b}$ also increases most at low altitudes, especially below $150 \mathrm{~km}$. While the precipitating particles make little difference to the ion densities at high altitude, the effect on neutral winds can be transferred from the low altitudes to the high altitudes due to the effects of viscosity, and consequently $R_{2}$ increases in all altitudes. In the polar cap, neither the ion density, nor the electric field changes, and therefore the in situ forces change little. Here, one would expect little change of the neutral winds. However, Figures $9 \mathrm{c}$ and $9 \mathrm{~d}$ show that the polar cap neutral winds increase at all altitudes. The possible reason is that the neutral wind is dominated by rotational flow in the polar region [Thayer and Killeen, 1991] and the increasing neutral wind at dusk could induce the increase of neutral wind in the polar cap through advection to maintain the high vorticity.

[27] There is a strong asymmetry in the neutral winds between the dusk and dawn sector, caused by both the distribution of electric fields and the Coriolis force [FullerRowell et al., 1984; McCormac et al., 1987; Niciejewski et al., 1996]. On the duskside, the potential creates ion flows with a vorticity of the same sense as the Coriolis force, so they combine to overwhelm the pressure gradient forces. On the dawnside, the ion flow vorticity is in the opposite sense as Coriolis, so the pressure gradient is the dominant force. To check this asymmetry, we examine the average neutral wind speed in the duskside and the dawnside for two levels of auroral forcing. Figure 10 shows that $V_{i}$ (dusk) is $50 \%$ bigger than $V_{i}$ (dawn) in magnitude at $250 \mathrm{~km}$ altitude. This difference is observed in the Weimer [1996] patterns 


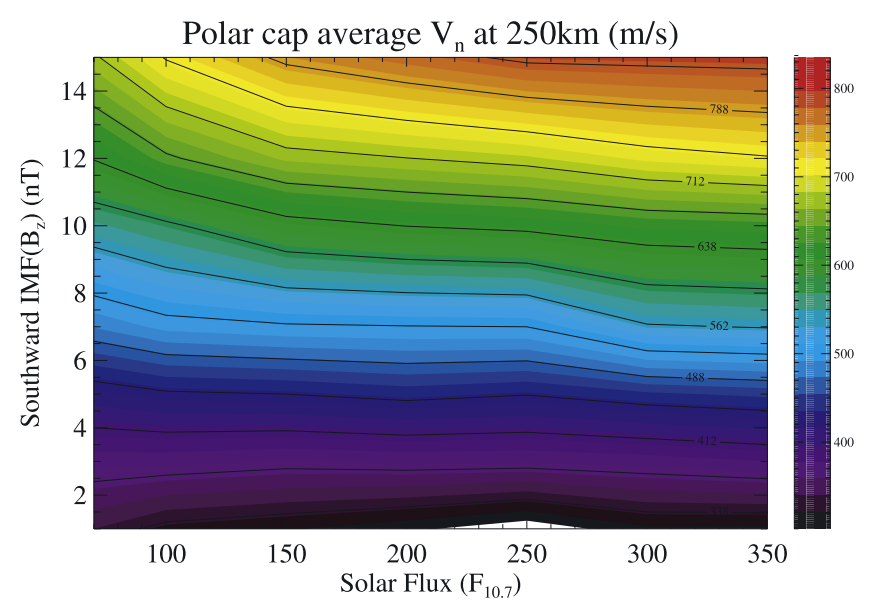

Figure 12. $\operatorname{RMS}\left(V_{n}\right)$ magnitude in polar cap (poleward $\left.80^{\circ}\right)$ at $250 \mathrm{~km}$ altitude as a function of $F_{10.7}$ and southward $\operatorname{IMF}\left(B_{z}\right)$ magnitude.

(Figure 4) and is thought to be due to the gradient in the solar EUV driven Hall conductance [Ridley et al., 2004]. When the HP is $10 \mathrm{GW}$, on the dawnside, $V_{n}(\max )$ happens around $200 \mathrm{~km}$ altitude and $R_{2}$ (dawn) is negative, which means $V_{i}$ and $V_{n}$ are antiparallel and the neutral winds are driven primarily by the pressure gradient. On the duskside, $V_{n}(\max )$ happens at $350 \mathrm{~km}$, and at most altitudes $R_{2}$ (dusk) is positive, which indicates $V_{i}$ and $V_{n}$ are parallel and could be the consequence of strong ion-drag. When the HP increases to $100 \mathrm{GW}$, as shown in Figure 10c, $V_{n}$ (dusk) increases substantially, especially below $150 \mathrm{~km}$, while the magnitude of $V_{i}$ (dusk) is about the same. On the dawnside, $R_{2}$ changes to be positive at all altitudes, as shown in Figure 10d, implying the formation of the dawn cell and the rotation of $V_{n}$ (dawn). This analysis shows that, not only is there a dawn-dusk asymmetry in the neutral wind circulation, but the reaction and sensitivity to the change of HP are also asymmetrical.

\subsection{Quantitative Results}

[28] To quantify the effects and provide a summary of the dependence of polar cap winds on the solar activity and southward IMF $B_{z}$, we calculate the magnitude of the polar cap average (poleward of $80^{\circ}$ ) neutral winds at $250 \mathrm{~km}$ altitude as a function of $F_{10.7}$ and southward $B_{z}$. The top three panels of Figure 11 show that the magnitude of the polar cap winds have a positive correlation with the magnitude of the southward $B_{z}$ and increasing sensitivity with $F_{10.7}$. The dependence on $F_{10.7}$ is more complex, as shown in the bottom panels. When $B_{z}=-1 \mathrm{nT}$, there is a negative correlation with $F_{10.7}$, which was also shown by Killeen et al. [1995] who explained it as caused by the occasional sunward flows in the central polar cap associated with positive $B_{z}$. This could be true in observations but not for our simulation, where we keep $B_{z}=-1 \mathrm{nT}$. Our interpretation is that when the southward $B_{z}$ is small and $F_{10.7}$ is increasing, the ion-drag force, which acts as a negative force to neutral winds in the polar cap region (as we discuss in section 3.2.), increases and pulls the neutral wind back. When the southward $B_{z}$ and the neutral velocity are big, the nonlinear advection term, which is in the opposite direction of the ion-drag force [Killeen et al., 1995], would be important and make the neutral winds increase. One main discrepancy between our results and Killeen et al. [1995] is the sensitivity to $F_{10.7}$ when $B_{z}$ is $-5 \mathrm{nT}$ and $-10 \mathrm{nT}$, which is much smaller in our results $(0.139 \mathrm{~m} / \mathrm{s}, 0.313 \mathrm{~m} / \mathrm{s}$ per unit of $\left.F_{10.7}\right)$ than the FPI observations $(1.13 \mathrm{~m} / \mathrm{s}, 1.68 \mathrm{~m} / \mathrm{s}$ per unit of $F_{10.7}$ ). One of the reasons is that the slopes (increase rate of neutral wind with $F_{10.7}$ ) shown by Killeen et al. [1995] are not the true independent sensitivity of the polar cap wind to solar flux indices since some of the slope is due to the correlated increases of $\mathrm{Kp}$ within the bin range (2 units of $\mathrm{Kp}$ ) [Killeen et al., 1995]. Another reason is the difference of time: our simulation is restricted to the equinox seasons, but the FPI observations cover all seasons. Therefore some of the sensitivity in the work of Killeen et al. [1995] could also be due to the seasonal variation.

[29] In Figure 12, we plot neutral winds in a two dimensional format to show the entire dependence. It is obvious that the IMF $B_{z}$ affects the neutral winds with more efficiency than $F_{10.7}$, but the dependence on $F_{10.7}$ is more complex.

[30] Figure 13 shows that the polar cap winds have a positive correlation with the HP at $160 \mathrm{~km}$ altitude when $F_{10.7}=150$ and IMF $B_{y}=0 \mathrm{nT}, B_{z}=-5 \mathrm{nT}$. As we know, the HP index is associated with the Kp index and Maeda et al. [1989] showed a linear relationship between Kp and HP

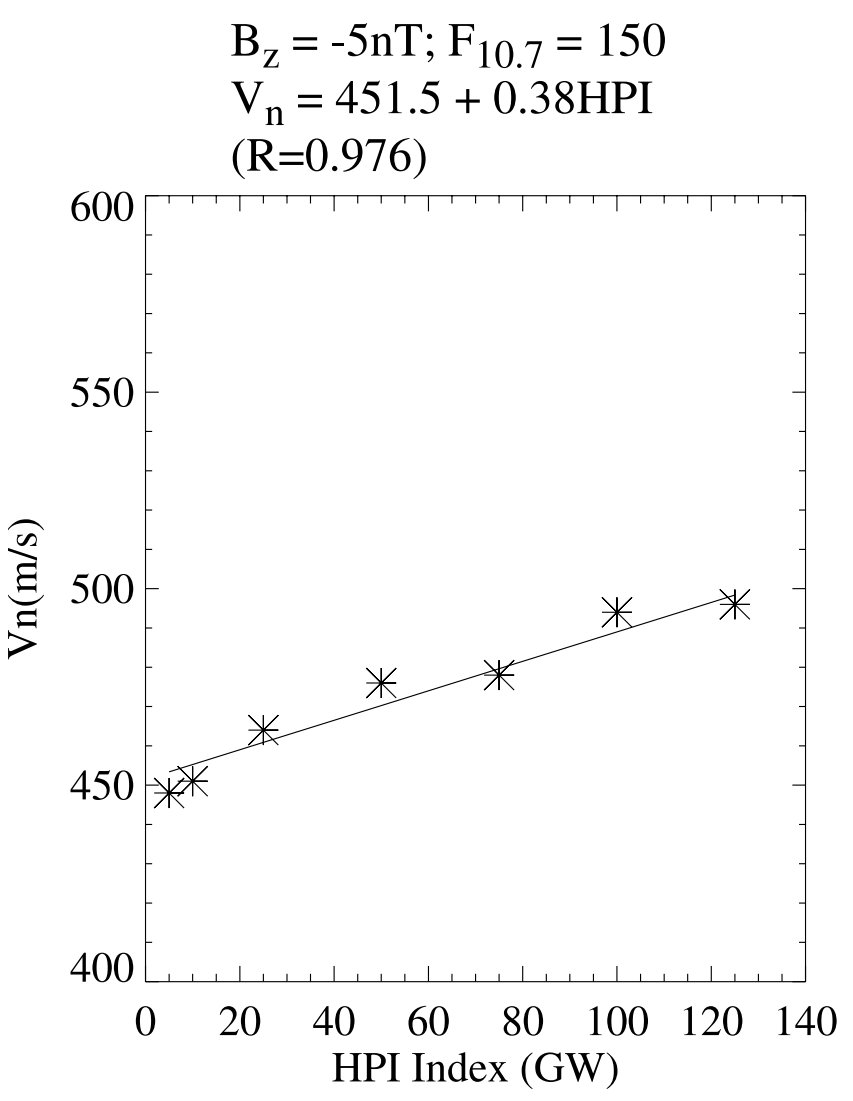

Figure 13. Linear fit to the antisunward polar cap wind magnitudes at $150 \mathrm{~km}$ altitude when HP changes and holding $F_{10.7}=150$, IMF $B_{z}=-5 \mathrm{nT}$. The corresponding equation with linear correlation coefficient is at the top of the figure. 
(A) $\mathrm{By}=10 \mathrm{nT}, \mathrm{Bz}=0 \mathrm{nT}$

Potential(V) at 298.6 km Altitude 19-MAR-02 00:00:00.000

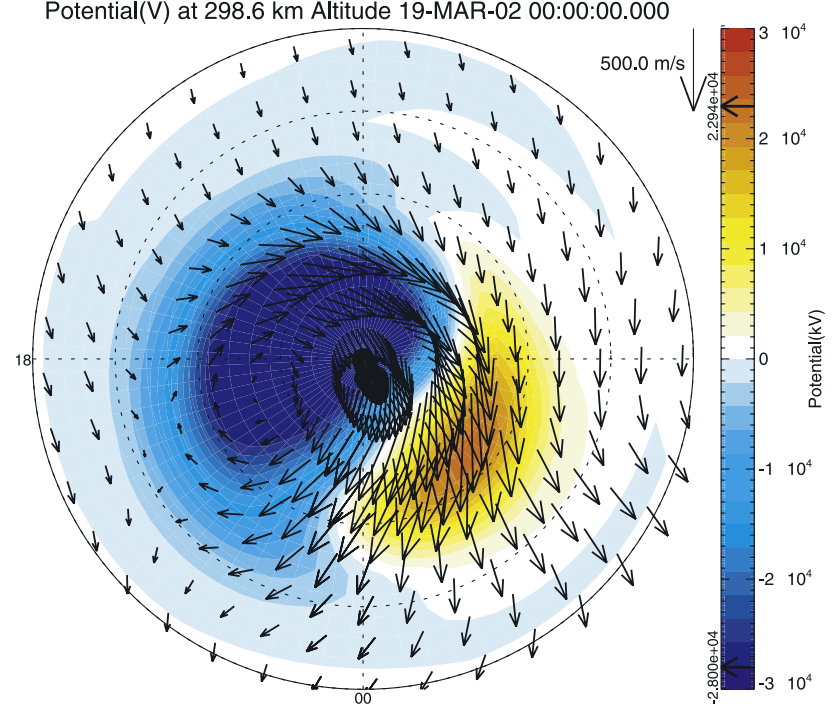

(C) $\mathrm{By}=0 \mathrm{nT}, \mathrm{Bz}=10 \mathrm{nT}$

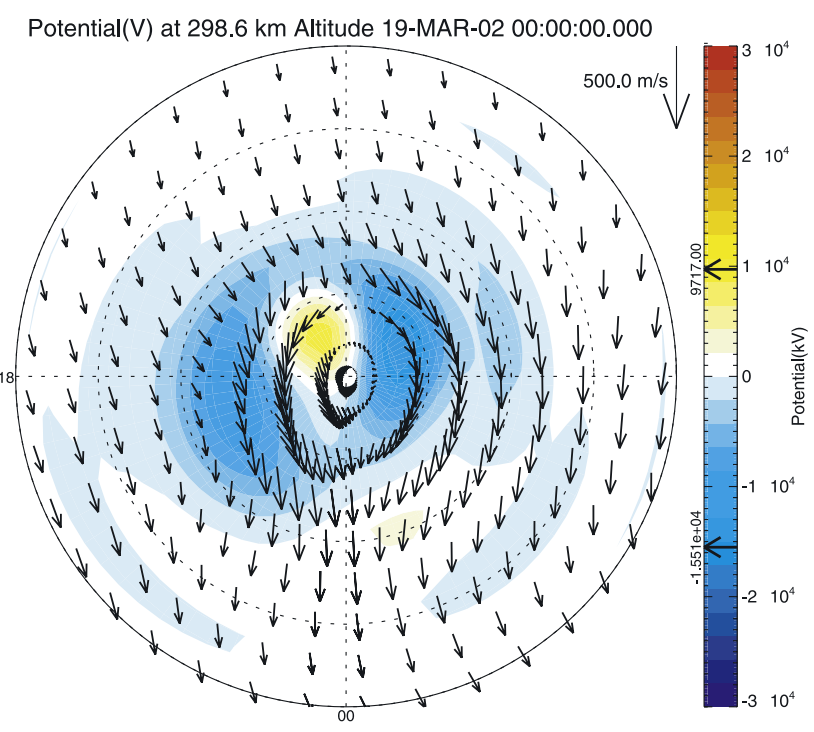

(B) $\mathrm{By}=-10 \mathrm{nT}, \mathrm{Bz}=0 \mathrm{nT}$

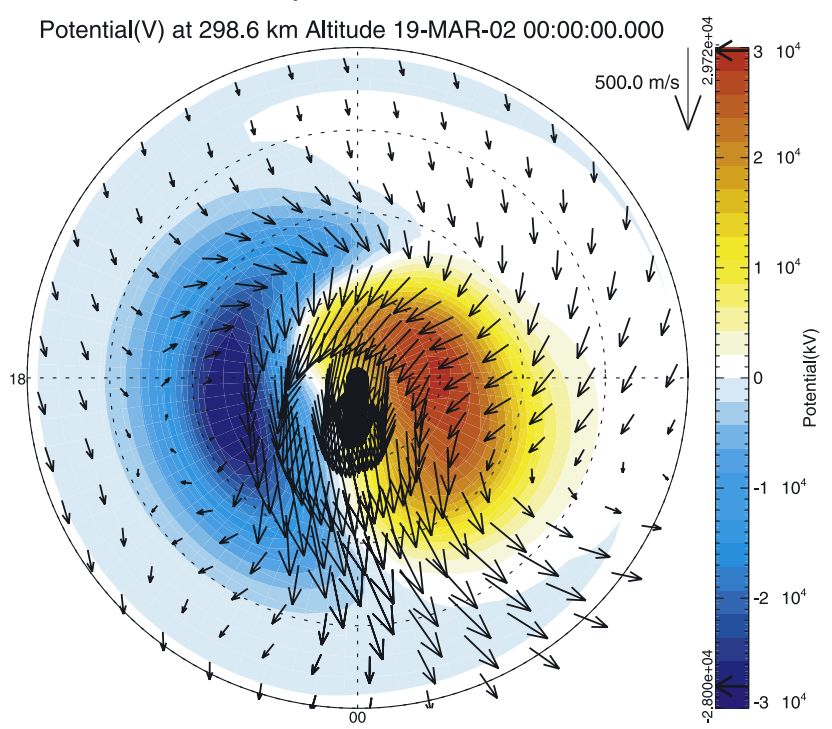

(D) $\mathrm{By}=0 \mathrm{nT}, \mathrm{Bz}=20 \mathrm{nT}$

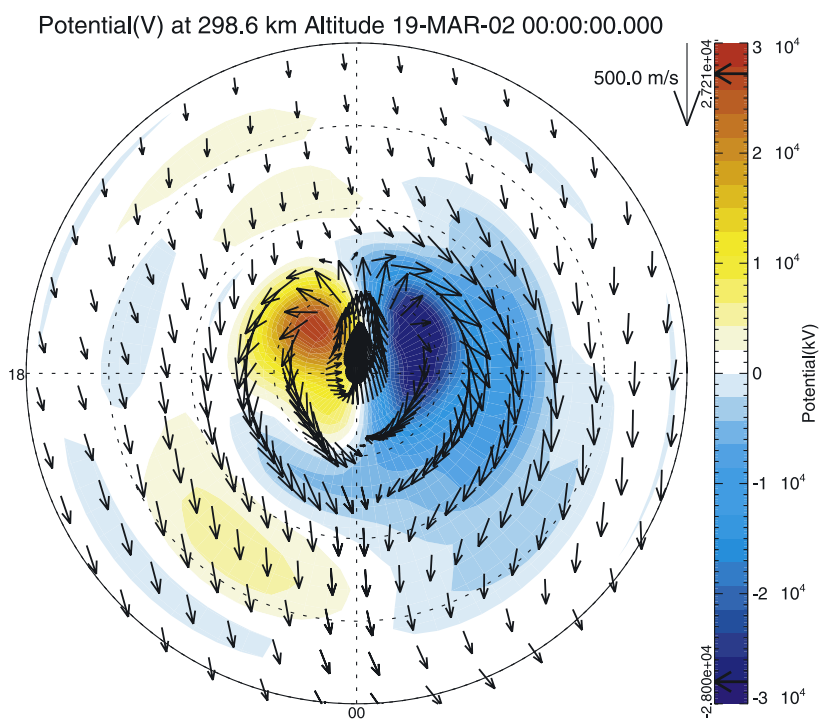

Figure 14. The effect of IMF $B_{y}$ to the polar region neutral winds when IMF $B_{y}$ changes from (a) $10 \mathrm{nT}$ to (b) $-10 \mathrm{nT}$ and holding $B_{y}=0 \mathrm{nT}, F_{10.7}=150, \mathrm{HP}=10 \mathrm{GW}$. The effect of northward IMF $B_{z}$ to the polar region neutral winds when IMF $B_{z}$ changes from (c) $10 \mathrm{nT}$ to (d) $20 \mathrm{nT}$ and holding $B_{y}=0 \mathrm{nT}$, $F_{10.7}=150, \mathrm{HP}=10 \mathrm{GW}$. The vectors show the horizontal neutral winds and the arrows present the directions. The color contours show the distribution of polar cap potential.

using NOAA data. However, we find that the effect of HP to the polar cap winds in our results is not as strong as that of Kp, shown by Killeen et al. [1995]. The possible reason is that the change of $\mathrm{Kp}$ is related to the change of both HP and the polar cap potential, and the polar cap potential can affect the polar cap winds strongly by changing the ion drifts. Therefore it is reasonable that the effect of $\mathrm{Kp}$ on the neutral wind is stronger than that of HP.

\subsection{Under Other IMF Orientations}

[31] While the southward IMF $B_{z}$ is primary driver of magnetic activity, $B_{y}$ and northward $B_{z}$ are also related to some interesting features in the neutral wind circulation. In order to illustrate these features, some qualitative results are presented in this section.

[32] A number of observations about the differences of convection pattern caused by the changes in the IMF $B_{y}$ have been carried out since 3 decades ago [Heppner, 1972] and these measurements were theoretically explained in terms of the dayside merging between IMF and geomagnetic field [Crooker, 1979; Cowley, 1981]. Figures 14a and $14 \mathrm{~b}$ show that in the northern hemisphere, the dawn (dusk) convection cell is enhanced when $B_{y}$ is negative 
(positive), which is consistent with Heppner and Maynard [1987]. The corresponding changes of neutral winds are in good agreement with Thayer et al. [1987] and Richmond et al. [2003]. The $B_{y}$ positive winds exhibit strong antisunward flow in the early morning section and an expanded dusk cell convection. In response to the effect of Coriolis force, the $B_{y}$ negative winds are not exactly mirror reflections of the $B_{y}$ positive winds. Although for the $B_{y}$ negative case, the dusk cell is pushed back and the flow turns from antisunward to poleward on the dawnside, there is no well-formed cell on the dawnside as happens on the duskside for the $B_{y}$ positive case.

[33] For northward IMF $B_{z}$ conditions, the plasma convection patterns are more complex and less understood than other situations. Multiple flow reversals and sunward flows are observed in the polar cap, which is interpreted as multicell convection patterns [Burke et al., 1979; Potemra et al., 1984] and distorted 2-cell patterns [Heppner and Maynard, 1987]. Our GITM model obtains the the convection patterns from an empirical model [Weimer, 1996]. As shown in Figures $14 \mathrm{c}$ and $14 \mathrm{~d}$, for northward IMF, Weimer [1996] presents multicell convection patterns. Through ion drag forcing, the neutral winds flow sunward at the highest latitudes near noon, which agrees with the observations [Niciejewski et al., 1994]. When the northward $B_{z}$ increases from $10 \mathrm{nT}$ to $20 \mathrm{nT}$, the cross-polar cap potential rises from $20 \mathrm{kv}$ to $60 \mathrm{kv}$, the distribution of polar cap potential becomes more symmetric and the sunward neutral flow is enhanced and expanded.

\section{Summary and Conclusions}

[34] We use GITM to investigate the thermospheric neutral winds and their relationship to the high-latitude ionospheric convection, auroral precipitation, and solar activity. The analysis of a large number of idealized conditions has led to the following conclusions:

[35] 1. The neutral winds' ramp-up time decreases with altitude, as a consequence of the increase in the relative significance of the ion drag force. Above $120 \mathrm{~km}$, after 12 hours running, the neutral winds reach steady state.

[36] 2. The duskside vortex and antisunward polar cap neutral winds are prominent and become stronger with increasing altitude. Our model results are in good agreement with WINDII observations.

[37] 3. The convection E-field under the southward IMF $B_{z}$ conditions strongly affect the neutral winds, specifically in the dusk cell and polar cap region. Although the dawn cell does not form, the effect of ion-drag is detectable on the dawnside. When the IMF $B_{z}$ changes from -1 to $-10 \mathrm{nT}$, in the auroral region, both $\left|V_{n}\right|$ and $\left|V_{i}\right|$ increase more than $50 \%$, and $R_{2}$ (correlation between the neutral and ionospheric convection velocities) increases, while the ratio $R_{1}$ (ratio of the mean wind speed to the mean ionospheric convection speed) changes little. In the polar cap region, above around $160 \mathrm{~km}$ altitude, $\left|V_{n}\right|$ is larger than $\left|V_{i}\right|$, since the ion flow is in the same direction as the neutral pressure gradient in the polar cap.

[38] 4. When $F_{10.7}$ increases from 70 to 250 , in the auroral region, $\left|V_{n}\right|$ increases close to $20 \%$ at $300 \mathrm{~km}$ altitude. Because both the pressure gradient and the electron density increase with $F_{10.7}$, the neutral wind dependence on
$F_{10.7}$ is quite complex in regions where the ion drag and pressure gradient forces are opposite. At high altitudes, $R_{2}$ increases with $F_{10.7}$, which indicates that the change of iondrag force is dominant. At low altitudes, $R_{2}$ decreases with $F_{10.7}$, which means that the pressure gradient force increases more than the ion-drag force.

[39] 5. The impact of HP on the low-altitude thermospheric winds is pronounced. At $150 \mathrm{~km}$ altitude, the neutral wind magnitude increases $30 \%$ at auroral latitudes. When $\mathrm{HP}$ is enhanced from 10 to $100 \mathrm{GW}$, a dawn cell forms, concurrent with an enhancement in the dusk cell.

[40] 6. The dusk and dawn cells show an apparent asymmetry both in the average neutral winds and the sensitivity of neutral winds to the HP. Partially, this is due to the asymmetric distribution of ion convection and the Coriolis force.

[41] 7. We show that at $250 \mathrm{~km}$ altitude, southward IMF $B_{z}$ has a positive correlation with the magnitude of the polar cap winds and the sensitivity increases with $F_{10.7}$. A negative correlation between $V_{n}$ and $F_{10.7}$ with small southward IMF $B_{z}$ becomes positive when the southward IMF $B_{z}$ increases. This change is possibly due to the momentum balance between ion-drag and advection.

[42] 8. In the northern hemisphere, the dawn (dusk) convection cell is enhanced when $B_{y}$ is negative (positive). The $B_{y}$ positive winds exhibit strong antisunward flow in the early morning section and an expanded dusk cell convection. In response to the effect of the Coriolis force, the $B_{y}$ negative winds are not exactly mirror reflections of the $B_{y}$ positive winds. For northward IMF Bz, the neutral winds flow sunward at the highest latitudes near noon. When the northward $B_{z}$ increases from $10 \mathrm{nT}$ to $20 \mathrm{nT}$, the distribution of the polar cap potential becomes more symmetric and the sunward neutral flow is enhanced and expanded.

\section{Appendix A: Horizontal Momentum Equations in GITM Model}

[43] In the thermosphere the neutrals are treated as having the same horizontal velocity, but individual vertical velocities $\mathbf{u}_{s}$. This is because above about $120 \mathrm{~km}$ altitude, the turbulent mixing becomes very small, and the individual species start to become hydrostatically balanced, instead of all the species having the same hydrostatic fall-off. They are described in detail by Ridley et al. [2006]. In rotating spherical coordinates the eastward momentum equation is

$$
\begin{aligned}
\frac{\partial u_{\phi}}{\partial t} & +u_{r} \frac{\partial u_{\phi}}{\partial r}+\frac{u_{\theta}}{r} \frac{\partial u_{\phi}}{\partial \theta}+\frac{u_{\phi}}{r \cos \theta} \frac{\partial u_{\phi}}{\partial \phi}+\frac{1}{r \cos \theta} \frac{\partial \mathcal{T}}{\partial \phi}+\frac{\mathcal{T}}{\rho r \cos \theta} \frac{\partial \rho}{\partial \phi} \\
& =\frac{\mathcal{F}_{\phi}}{\rho}+\frac{u_{\phi} u_{\theta} \tan \theta}{r}-\frac{u_{r} u_{\phi}}{r}+2 \Omega u_{\theta} \sin \theta-2 \Omega u_{r} \cos \theta, \quad(\mathrm{A} 1)
\end{aligned}
$$

The northward momentum equation becomes

$$
\begin{aligned}
\frac{\partial u_{\theta}}{\partial t} & +u_{r} \frac{\partial u_{\theta}}{\partial r}+\frac{u_{\theta}}{r} \frac{\partial u_{\theta}}{\partial \theta}+\frac{u_{\phi}}{r \cos \theta} \frac{\partial u_{\theta}}{\partial \phi}+\frac{1}{r} \frac{\partial \mathcal{T}}{\partial \theta}+\frac{\mathcal{T}}{\rho r} \frac{\partial \rho}{\partial \theta} \\
& =\frac{\mathcal{F}_{\theta}}{\rho}-\frac{u_{\phi}^{2} \tan \theta}{r}-\frac{u_{\theta} u_{r}}{r}-\Omega^{2} r \cos \theta \sin \theta-2 \Omega u_{\phi} \sin \theta .
\end{aligned}
$$


In the above two equations, the force terms due to ionneutral friction and viscosity are

$$
\begin{aligned}
& \mathcal{F}_{\theta}=\rho_{i} v_{i n}\left(v_{\theta}-u_{\theta}\right)+\frac{\partial}{\partial r} \eta \frac{\partial u_{\theta}}{\partial r} \\
& \mathcal{F}_{\phi}=\rho_{i} v_{i n}\left(v_{\phi}-u_{\phi}\right)+\frac{\partial}{\partial r} \eta \frac{\partial u_{\phi}}{\partial r}
\end{aligned}
$$

Only the viscosity due to the radial shear of the horizontal wind is included. The first term on the right side is the ion drag.

[44] The ion momentum equation assumes that $\frac{\partial \mathbf{v}}{\partial t}$ and ion advection are small enough to be neglected. In addition, the ion-electron collision frequency is assumed to be negligible. Using these assumptions, the momentum equation can be solved for the ion velocity:

$$
\begin{aligned}
\mathbf{v}= & \mathbf{u} \cdot \mathbf{b}+\frac{1}{\nu_{i n}}\left(\mathbf{g} \cdot \mathbf{b}-\frac{\nabla\left(P_{i}+P_{e}\right) \cdot \mathbf{b}}{\rho_{i}}\right) \\
& +\frac{\rho_{i} \nu_{i n} \mathbf{A}+e N_{e} \mathbf{A} \times \mathbf{B}}{\rho_{i}^{2} \nu_{i n}^{2}+e^{2} N_{e}^{2} B^{2}},
\end{aligned}
$$

where

$$
\mathbf{A}=\rho_{i} \mathbf{g}_{\perp}+e N_{e} \mathbf{E}_{\perp}-\nabla\left(P_{i}+P_{e}\right)_{\perp}+\rho_{i} v_{i n} \mathbf{u}_{\perp},
$$

[45] Acknowledgments. This research was supported by NSF through grants ATM-0077555 and ATM-0417839, the DoD MURI program grant F4960-01-1-0359, and NASA grant NNG04GK18G.

[46] Arthur Richmond thanks Barbara Emery and David Rees for their assistance in evaluating this paper.

\section{References}

Akasofu, S.-I. (1964), The development of the auroral substorm, Planet. Space Sci., 101, 273.

Akasofu, S. I. (1976), Recent progress in studies of DMSP auroral phtographs, Space Sci. Rev., 19, 169.

Aruliah, A. L., D. Rees, and T. J. Fuller-Rowell (1991), The combined effect of solar and geomagnetic activity on high latitude thermospheric neutral winds, part I, Observations, J. Atmos. Terr. Phys., 53, 4677.

Axford, W. I., and C. O. Hines (1961), A unifying theory of high-latitude geophysical phenomena and gemagnetic storms, Can. J. Phys., 39, 1433.

Brekke, A., J. R. Doupnik, and P. M. Banks (1974), Incoherent scatter measurements of $E$ region conductivities and currents in the auroral zone, J. Geophys. Res., 79, 3773.

Burke, W. J., M. C. Kelley, R. C. Sagalyn, M. Smiddy, and S. T. Lai (1979), Polar cap electric field structures with a northward interplanetary magnetic field, Geophys. Res. Lett., 6, 21, 1979.

Cowley, S. W. H. (1981), Magnetospheric asymmetries associated with the y-component of the IMF, Planet. Space Sci., 29, 79.

Crooker, N. U. (1979), Dayside merging and cusp geometry, J. Geophys. Res., 84, 951.

Deng, W., T. L. Killeen, A. G. Burns, R. G. Roble, J. A. Slavin, and L. E. Wharton (1993), The effects of neutral inertia on ionospheric currents in the high-latitude thermosphere following a geomagnetic storm, J. Geophys. Res., 98, 7775.

Emmert, J. T., B. G. Fejer, and D. P. Sipler (2003), Climatology and latitudinal gradients of quiet time thermospheric neutral winds over Millstone Hill from Fabry-Perot interferometer measurements, J. Geophys. Res., 108(A5), 1196, doi:10.1029/2002JA009765.

Fuller-Rowell, T. J., and D. Evans (1987), Height-integrated Pedersen and Hall conductivity patterns inferred from TIROS-NOAA satellite data, J. Geophys. Res., 92, 7606.

Fuller-Rowell, T. J., D. Rees, S. Quegan, G. J. Bailey, and R. J. Moffett (1984), The effect of realistic conductivities on the high-latitude neutral thermospheric circulation, Planet. Space Sci., 32, 469.

Gary, J. B., R. A. Heelis, W. B. Hanson, and J. A. Slavin (1994), Fieldaligned Poynting flux observations in the high-latitude ionosphere, J. Geophys. Res., 99, 11,417.
Gombosi, T. I., et al. (2004), Solution adaptive MHD for space plasmas: Sun-to-Earth simulations, Comput. Sci. Eng., 6, 14.

Hardy, D. A., M. S. Gussenhoven, and E. Holeman (1985), A statistical model of auroral electron precipitation, J. Geophys. Res., 90, 4229.

Hedin, A. E. (1992), Horizontal wind model (HWM) (1990), Planet. Space Sci., 40, 556.

Hedin, A. E., N. W. Spencer, and T. L. Killeen (1988), Empirical global model of upper thermosphere winds based on Atmosphere and Dynamics Explorer satellite data, J. Geophys. Res., 93, 9959.

Hedin, A. E., et al. (1996), Empirical wind model for the upper, middle and lower atmosphere, J. Atmos. Terr. Phys., 58, 1421.

Heppner, J. P. (1972), Polar cap electric field distributions related to the interplanetary magnetic convection pattern, J. Geophys. Res., 77, 4877.

Heppner, J. P., and N. C. Maynard (1987), Empirical high-latitude electric field models, J. Geophys. Res., 92, 4467.

Killeen, T. L., and R. G. Roble (1984), An analysis of the high-latitude thermospheric wind pattern calculated by a thermospheric general circulation model: 1. Momentum forcing, J. Geophys. Res., 89, 7509.

Killeen, T. L., R. A. Heelis, P. B. Hays, N. W. Spencer, and W. B. Hanson (1985), Neutral motions in the polar thermosphere for northward interplanetary magnetic field, Geophys. Res. Lett., 12, 159.

Killeen, T. L., R. G. Roble, and N. W. Spencer (1987), A computer model of global thermospheric winds and temperatures, Adv. Space Res., 7, 207.

Killeen, T. L., Y. I. Won, R. J. Niciejewski, and A. G. Burns (1995), Upper thermosphere winds and temperatures in the geomagnetic polar cap: Solar cycle, geomagnetic activity, and interplanetary magnetic field dependencies, J. Geophys. Res., 100, 21,327.

Kunitake, M., and K. Schlegel (1991), Neutral winds in the lower thermosphere at high latitudes from five years of EISCAT data, Ann. Geophys., $9,143$.

Lathuillère, C., J. Lilensten, W. Gault, and G. Thuillier (1997), Meridional wind in the auroral thermosphere: Results from EISCAT and WINDII-O $\left({ }^{1} D\right)$ coordinated measurements, J. Geophys. Res., 102, 4487.

Maeda, S., T. J. Fuller-Rowell, and D. S. Evans (1989), Zonally averaged dynamical and compositional response of the thermosphere to auroral activity during September 18-24, 1984, J. Geophys. Res., $94,16,869$.

McCormac, F. G., T. L. Killeen, J. P. Thayer, G. Hernandez, C. R. Tschan, J. J. Ponthieu, and N. W. Spencer (1987), Circulation of the polar thermosphere during geomagnetically quiet and active times as observed by Dynamics Explorer 2, J. Geophys. Res., 92, 10,133.

McCormac, F. G., T. L. Killeen, and J. P. Thayer (1991), The influence of IMF $B_{y}$ on the high-latitude thermospheric circulation during northward IMF, J. Geophys. Res., 96, 115.

Meriwether, J. W. J. (1983), Observations of thermospheric dynamics at high latitude from ground and space, Radio Sci., 18, 1035.

Meriwether, J. W. J., and P. Shih (1987), On the nighttime signatures of thermospheric winds observed at Sondrestrom, Greenland, as correlated with interplanetary magnetic field parameters, Ann. Geophys., $5 A, 329$.

Mikkelsen, I. S., T. S. Jorgensen, M. C. Kelley, M. F. Larsen, E. Pereira, and J. Vickery (1981), Neutral winds and electric fields in the dusk auroral oval: 1. Measurements, J. Geophys. Res., 86, 1513.

Niciejewski, R. J., T. L. Killeen, R. M. Johnson, and J. P. Thayer (1992), The behaviour of the high-latitude $f$-region neutral thermosphere in relation to IMF parameters, Adv. Space Res., 12, 215.

Niciejewski, R. J., T. L. Killeen, and Y. Won (1994), Observations of neutral winds in the polar cap during northward IMF, J. Atmos. Terr. Phys., 56, 285.

Niciejewski, R. J., T. L. Killeen, and S. C. Solomon (1996), Observations of thermospheric horizontal neutral winds at Watson Lake, Yukon Territory $\left(\wedge=65^{\circ} \mathrm{N}\right), J$. Geophys. Res., 101, 241.

Peymirat, C., A. D. Richmond, and R. G. Roble (2002), Neutral wind influence on the electrodynamic coupling between the ionosphere and the magnetosphere, J. Geophys. Res., 107(A1), 1006, doi:10.1029/ 2001JA900106.

Potemra, T. A., L. J. Zanetti, P. F. Bythrow, A. T. Y. Lui, and T. Iijima (1984), B(y)-dependent convection patterns during northward interplanetary magnetic field, J. Geophys. Res., 89, 9753.

Rees, D., T. J. Fuller-Rowell, R. Gordon, T. L. Killeen, P. B. Hays, and L. W. N. W. Spencer (1983), A comparison of thermospheric wind observations from the dynamics explorer spacecraft with the predictions of a global time-dependent model, Planet. Space Sci., 31, 1299.

Rees, D., et al. (1986), A theroretical and empirical study of the response of the high latitude thermosphere to the sense of the "Y" component of the interplanetary magnetic field, Planet. Space Sci., 34, 1.

Richmond, A. D. (1992), Assimilative mapping of ionospheric electrodynamics, Adv. Space Res., 12, 59.

Richmond, A. D. (1995), Ionospheric electrodynamics using magnetic apex coordinates, J. Geomagn. Geoelectr., 47, 191. 
Richmond, A. D., and Y. Kamide (1988), Mapping electrodynamic features of the high-latitude ionosphere from localized observations: Technique, J. Geophys. Res., 93, 5741.

Richmond, A. D., C. Lathuillère, and S. Vennerstroem (2003), Winds in the high-latitude lower thermosphere: Dependence on the interplanetary magnetic field, J. Geophys. Res., 108(A2), 1066, doi:10.1029/ 2002JA009493.

Ridley, A. J., G. Crowley, and C. Freitas (2000), A statistical model of the ionospheric electric potential, Geophys. Res. Lett., 27, 3675.

Ridley, A. J., A. D. Richmond, T. I. Gombosi, D. L. D. Zeeuw, and C. R. Clauer (2003), Ionospheric control of the magnetospheric configuration: Thermospheric neutral winds, J. Geophys. Res., 108(A8), 1328, doi:10.1029/2002JA009464.

Ridley, A. J., T. I. Gombosi, and D. L. D. Zeeuw (2004), Ionospheric control of the magnetospheric configuration: Conductance, Ann. Geophys., 22, 567.

Ridley, A. J., Y. Deng, and G. Toth (2006), The global ionosphere-thermosphere model, J. Atmos. Sol. Terr. Phys., 68, 839.

Roble, R. G., R. E. Dickinson, E. C. Ridley, B. A. Emery, P. B. Hays, T. L. Killeen, and N. W. Spencer (1983), The high-latitude circulation and temperature structure of the thermosphere near solstice, Planet. Space Sci., 31, 1479 .

Roble, R. G., B. A. Emery, R. E. Dickinson, E. C. Ridley, T. L. Killeen, P. B. Hays, G. R. Carignan, and N. W. Spencer (1984), Thermospheric circulation, temperature, and compositional structure of the southern hemisphere polar cap during October-November 1981, J. Geophys. Res., 87, 9057.
Rothwell, P., R. Mountford, and G. Martelli (1974), Neutral wind modifications above $150 \mathrm{~km}$ altitude associated with the polar substorm, J. Atmos. Terr. Phys., 36, 1915.

Schunk, R. W., and A. F. Nagy (2000), Ionospheres, Cambridge Univ. Press, New York.

Sergeev, V. A., R. J. Pellinen, and T. I. Pulkkinen (1996), Steady magnetospheric convection: A review of recent results, Space Sci. Rev., 75, 551

Thayer, J. P., and T. L. Killeen (1991), Vorticity and divergence in the highlatitude upper thermosphere, Geophys. Res. Lett., 18, 701.

Thayer, J. P., T. L. Killeen, F. G. McCormac, C. R. Tschan, J. J. Ponthieu, and N. W. Spencer (1987), Thermospheric neutral wind signatures dependent on the east-west component of the interplanetary magnetic field for northern and southern hemispheres as measured by Dynamics Explorer-2, Ann. Geophys., 5A, 363.

Weimer, D. R. (1996), A flexible, IMF dependent model of high-latitude electric potential having "space weather" applications, Geophys. Res. Lett., 23, 2549.

Zhang, S. P., and G. G. Shepherd (2000), Neutral winds in the lower themosphere observed by WINDII during the April 4-5th, 1993 storm, Geophys. Res. Lett., 27, 1855.

Y. Deng and A. J. Ridley, Center for Space Environment Research, University of Michigan, Ann Arbor, MI 48109-2143, USA. (ydeng@ umich.edu; ridley@umich.edu) 